\title{
CEACAM1 regulates the IL-6 mediated fever response to LPS through the RP105 receptor in murine monocytes
}

\author{
Zhifang Zhang*, Deirdre La Placa, Tung Nguyen, Maciej Kujawski, Keith Le, Lin Li and John E. Shively* (D)
}

\begin{abstract}
Background: Systemic inflammation and the fever response to pathogens are coordinately regulated by IL- 6 and IL-1 $\beta$. We previously showed that CEACAM1 regulates the LPS driven expression of IL-1 $\beta$ in murine neutrophils through its ITIM receptor.

Results: We now show that the prompt secretion of IL-6 in response to LPS is regulated by CEACAM1 expression on bone marrow monocytes. Ceacam $1^{-1-}$ mice over-produce IL-6 in response to an i.p. LPS challenge, resulting in prolonged surface temperature depression and overt diarrhea compared to their wild type counterparts. Intraperitoneal injection of a ${ }^{64} \mathrm{Cu}$-labeled LPS, PET imaging agent shows confined localization to the peritoneal cavity, and fluorescent labeled LPS is taken up by myeloid splenocytes and muscle endothelial cells. While bone marrow monocytes and their

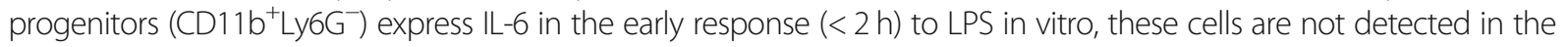
bone marrow after in vivo LPS treatment perhaps due to their rapid and complete mobilization to the periphery. Notably, tissue macrophages are not involved in the early IL-6 response to LPS. In contrast to human monocytes, TLR4 is not expressed on murine bone marrow monocytes. Instead, the alternative LPS receptor RP105 is expressed and recruits MD1, CD14, Src, VAV1 and $\beta$-actin in response to LPS. CEACAM1 negatively regulates RP105 signaling in monocytes by recruitment of SHP-1, resulting in the sequestration of PVAV1 and $\beta$-actin from RP105.
\end{abstract}

Conclusion: This novel pathway and regulation of IL- 6 signaling by CEACAM1 defines a novel role for monocytes in the fever response of mice to LPS.

Keywords: CEACAM1, IL-6, Fever, LPS, Monocytes, RP105, TLR4

\section{Introduction}

IL-6 is a central mediator of inflammation in response to a wide variety of stimuli including infection, stress and trauma [1]. Its receptor, IL-6R, is widely expressed, especially in the liver leading to the acute phase protein response [1], in the hypothalamus together with IL-1 $\beta$ leading to systemic fever [2], and in the gut leading to Th17 activation [3]. Chronic high levels of IL-6 are associated with aging, cancer, rheumatoid arthritis, neurodegenerative diseases, postmenopausal osteoporosis [4], and psoriasis [5] to name a few pathogenic conditions. As a result, activation of the IL-6 gene is under tight control, and an understanding of its regulation is fundamental to preventing a wide

\footnotetext{
*Correspondence: zzhang@coh.org; jshively@coh.org

Department of Molecular Imaging and Therapy, Beckman Research Institute of City of Hope, 1500E Duarte Road, Duarte CA91010, USA
}

range of pathologies [6]. We are especially interested in the regulation of the fever response that requires production of both IL-1 $\beta$ and IL-6, that together stimulate the production of PGE2 in the hypothalamus, leading to a drop in the core temperature of a few tenths of a degree [7]. Even more pronounced is the lowering of skin temperature that is perceived as "chills" followed by stimulation of the skeletal muscles or "shivering." The critical role of IL-6 in the fever response is exemplified in IL-6 KO mice that do not exhibit a fever in response to classical stimuli such as bacterial endotoxin, viruses, and the inflammatory cytokines TNF $\alpha$ and IL-1 $\beta$ [8].

Given the wide range of stimuli that elicit the IL- 6 response from essentially anywhere in the body, knowledge of the cells and mechanism of IL- 6 secretion is essential. However, more is known about the cells that respond to IL-6 than those that produce it, and its regulation remains

(c) The Author(s). 2019 Open Access This article is distributed under the terms of the Creative Commons Attribution 4.0 International License (http://creativecommons.org/licenses/by/4.0/), which permits unrestricted use, distribution, and 
an area of intense investigation. We hypothesize that this regulation must be widespread, especially at the interface between the epithelium where infections, trauma and stress are likely to occur, and the immune system. A candidate gene for this regulation is CEACAM1, a homotypic cell-cell adhesion molecule ubiquitously expressed in the epithelium, constitutively expressed in neutrophils, the most abundant leukocytes, and inducibly expressed in activated lymphocytes [9]. CEACAM1 has tissue specific, differential expression of mRNA splice forms, with an ITIM containing signaling domain expressed in the immune system and a shortened signaling domain lacking an ITIM in uninflamed epithelial cells [10]. Notably, the expression of the ITIM containing CEACAM1 splice form is strictly regulated in response to IFN $\gamma$ via IRF-1 [11]. In agreement with this role for CEACAM1, we have previously shown that CEACAM1 regulates granulopoiesis and the systemic response to Listeria monocytogenes infection via the G-CSFR-STAT3 pathway [12], and the IL-1 $\beta$ response to LPS in neutrophils by a TLR4-Syk pathway [13]. In both cases, CEACAM1 is recruited to an activated receptor (G-CSFR or TLR4), that when phosphorylated by a Src kinase on its ITIM, recruits SHP-1, which in turn, dephosphorylates the activated receptor. This is a general mechanism for CEACAM1 that has been implicated in the regulation of the insulin receptor in the liver [14], the EGFR in epithelial cells [15], and the BCR in B-cells [16, 17]. In this way, CEACAM1 can moderate the effect of the immune system on stimulated epithelial cells, and when absent, as in many cancers $[18,19]$, the result is chronic or exaggerated inflammation. The digestive tract, including the small and large intestine, and the liver, have the highest levels of CEACAM1 expression [20]. Since it is well known that LPS in the peritoneal cavity, mimicking leaky gut, leads to a rapid inflammatory and fever response [21] due to the combined actions of IL- 6 and IL-1 $\beta$, we speculated that an exaggerated response would be seen in $C E A C A M 1^{-/-}$mice, providing a model system to track down the cells responsible for IL-6 release.

The plasma levels of IL-6 in Ceacam1 $1^{-/}$mice in response to i.p. LPS were more than twice the amount of wild type mice at $24-48 \mathrm{~h}$, including the depression of body surface temperatures and overt diarrhea in $50 \%$ of the Ceacam1 $1^{-/-}$mice compared to none in the wild type controls. PET image analysis of mice injected i.p. with ${ }^{64} \mathrm{Cu}$-labeled-LPS exhibited LPS localization largely confined to the peritoneal cavity, while i.p. injection of fluorescent tagged LPS demonstrated staining in the spleen, lymph nodes and endothelial cells of skeletal muscle. Analysis of bone marrow cells revealed that a subset of bone marrow myeloid cells were rapidly mobilized to the spleen, perhaps explaining the controversy over the lack of IL-6 secreting myeloid cells in mice treated with LPS. In vitro analysis revealed that bone marrow monocytes and their progenitors produce IL- 6 in the early response $(<2 \mathrm{~h})$ to LPS while tissue macrophages do not. Unexpectedly, we found that TLR4, the prototypic LPS receptor of murine macrophages [22$24]$ and human monocytes and macrophages [25, 26] was not expressed on murine bone marrow monocytes. Instead, the alternate LPS receptor RP105, highly expressed on B-cells, was responsible for IL-6 secretion on murine bone marrow monocytes. We demonstrated that MD1, CD14, Src, VAV1 and $\beta$-actin are involved in the downstream signaling of RP105 and that CEACAM1 regulates RP105 signaling through recruitment of SHP-1 and sequestration of pVAV1 and $\beta$-actin from pRP105. We conclude that CEACAM1 negatively regulates IL-6 in the early phase response to LPS through the RP105 signaling pathway in murine monocytes, thus defining a novel role of CEACAM1 for monocytes in the fever response.

\section{Results}

\section{Genetic ablation of CEACAM1 leads to an exaggerated} IL-6 response to LPS

We previously showed that CEACAM1 regulates IL-1 $\beta$ production in LPS treated granulocytes in a TLR4-Syk specific manner [13]. Since IL-1 $\beta$ and IL-6 together mediate the fever response to LPS, we performed an in vivo challenge of wild type (WT) and Ceacam1 $1^{-1}$ mice with LPS injected i.p. Surface body temperature was measured as a sensitive indicator of the fever response along with serum multiplex cytokine levels to determine which, if any, were dysregulated in Ceacam1 ${ }^{-/-}$mice treated with LPS. Phenotypically, both WT and Ceacam1 $1^{-/-}$mice had depressed surface body temperatures, with the depression in Cea$\mathrm{caml}^{-/-}$mice significantly lower than in WT mice at both the $8 \mathrm{~h}$ and $24 \mathrm{~h}$ time points (Fig. 1a). Approximately $50 \%$ (9 out of 17) of Ceacam1 ${ }^{-/-}$mice developed overt diarrhea in comparison with none in wild type mice (Fig. 1b). Comparison of the serum levels of cytokines between Cea$\mathrm{cam}^{-/-}$and WT mice, revealed similar kinetics and levels for IL-1 $\beta$, TNF $\alpha$ and IFN $\gamma$, as well as others (not shown), while IL-6 levels were significantly elevated in Ceacam1 ${ }^{-1}$ mice over $24 \mathrm{~h}$, returning to baseline by $48 \mathrm{~h}$ (Fig. 1c-f). The results suggest that abrogation of CEACAM1 expression in mice dramatically increases their sensitivity to i.p. LPS by specific over-expression of IL-6.

\section{LPS distribution after i.p. Injection and IL-6 mRNA expression in mouse organs}

IL-6 is considered the critical proinflammatory cytokine for the febrile response, since neither IL-6 knock-out mice, nor animals treated with IL-6 antiserum develop fever upon peripheral immune stimulation $[8,27,28]$. Furthermore, it is understood that IL-6 acts in concert with IL-1 $\beta$ as an endogenous pyrogen during LPS-induced fever $[7,27]$. Although IL-6 is reported to be synthesized and secreted by many cell types, for example, monocytes and macrophages [29, 30], fibroblasts [31], brain endothelial 


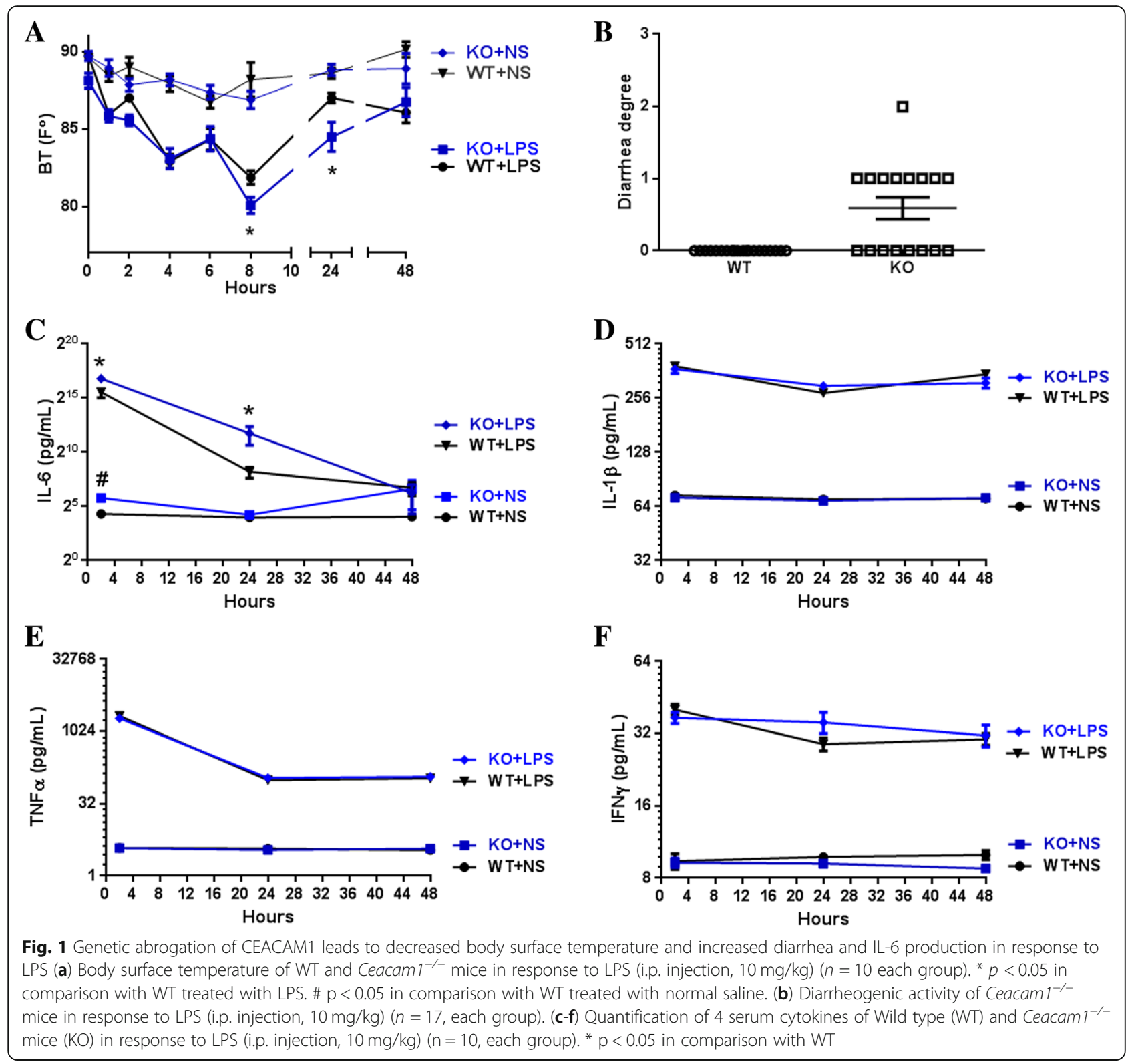

cells [32, 33], muscle cells [34], hepatocytes [35, 36], adipocytes [37], neurons [38, 39], microglial cells [40, 41] and astrocytes [42, 43], the source of serum IL-6 after i.p. treatment of LPS remains controversial [44].

As a first approach to determining the source of systemic production of IL-6, we injected ${ }^{64} \mathrm{Cu}$-labeled LPS i.p. into mice and performed PET imaging (Fig. 2a). This approach allows a quantitative measure of LPS localization over time. The results demonstrate that, excluding bladder secretion, ${ }^{64} \mathrm{Cu}$-labeled-LPS is mainly localized to the peritoneal cavity, including liver, kidney and thoracic lymph nodes at 1,2 , and $4 \mathrm{~h}$ time points, and is largely cleared via urinary excretion by $24 \mathrm{~h}$. Notably, very little bone activity was observed, indicating that secretion of IL- 6 by bone marrow cells (if any) must be indirect. Utilizing a similar chemical procedure to produce a fluorescent version of LPS, we generated FAM-labeled LPS that is considerably brighter and more stable than commercially available FITC-LPS. Thus, as a second approach to visualizing tissue targets of LPS, FAM-LPS was injected i.p. and multiple tissues collected for analysis by immunofluorescence analysis at 1 h. The results demonstrated high uptake into the spleen, lymph nodes, and the endothelial cells of skeletal muscle (Fig. 2b, d). Further analysis of the spleen cells labeled indicated that they were macrophages (Fig. 2c).

Since the first two approaches only indicate tissues of LPS uptake and not IL-6 production, we also measured IL-6 mRNA by qPCR of peritoneal tissues and other organs. Most peritoneal cavity tissues/organs including mesentery, peritoneal membranes, pancreas, and fatty tissues 

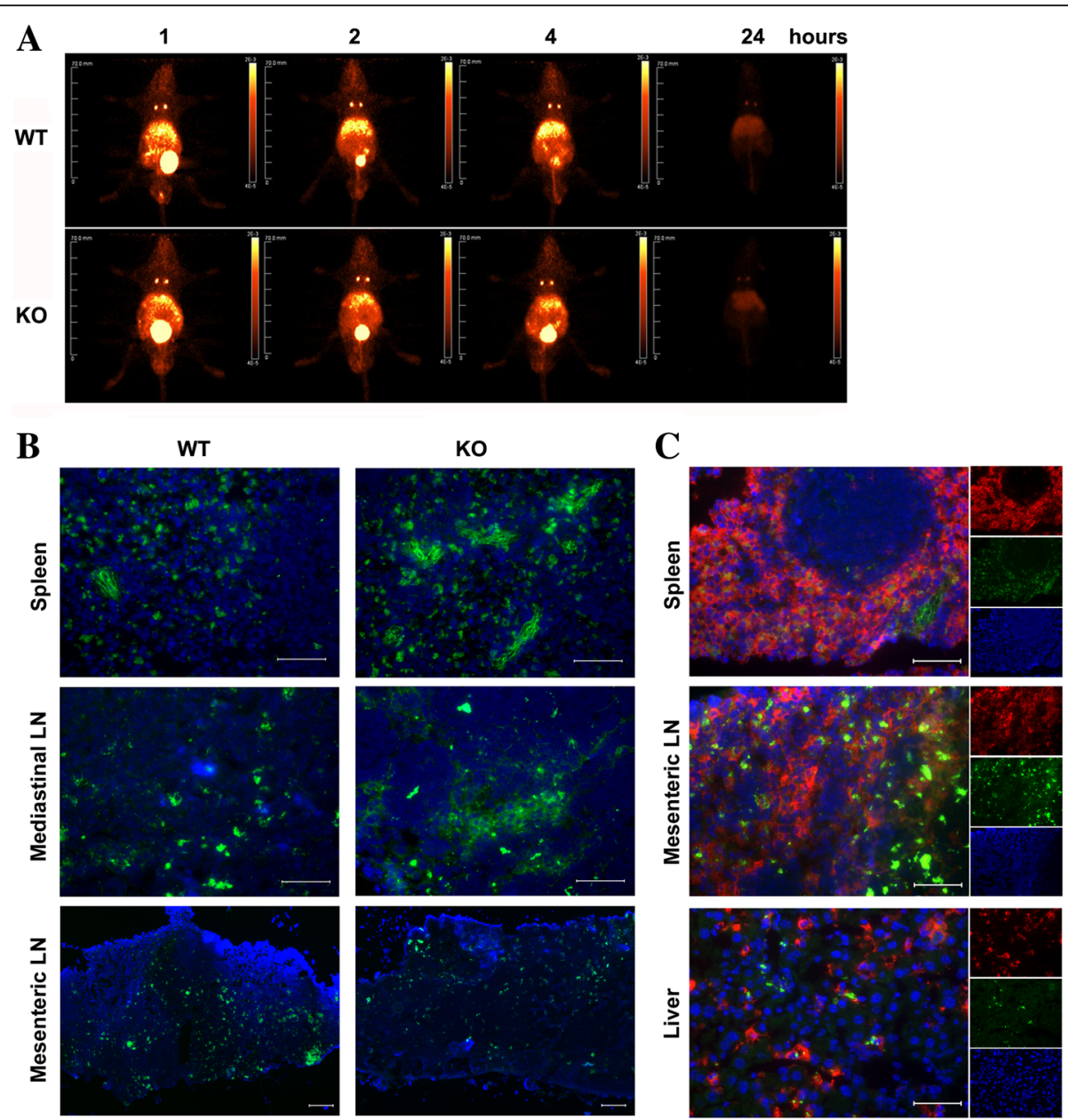

$\mathbf{D}$

Mediastinal LN

Kidney
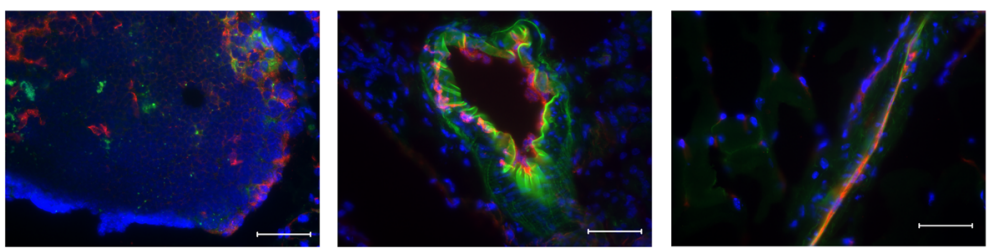

Fig. 2 Distribution of intraperitoneal injection of ${ }^{64} \mathrm{Cu}$-labeled LPS or FAM-LPS. (a) PET imaging of i.p. injection of ${ }^{64} \mathrm{Cu}$-labeled LPS over time. (bd) Immunofluorescent staining of selected tissues $1 \mathrm{~h}$ after i.p. injection of FAM-LPS. FAM labeled LPS (green). (c) Rat anti-mouse F4/80 followed by Alexa 647 goat anti-Rat antibody (red). (d) Rat anti-mouse CD31 followed by Alexa 647 goat anti-Rat antibody (red)

did not show any difference between WT and Ceacam1 ${ }^{-1-}$ mice, while omentum and small intestine exhibited a decrease in Ceacam1 ${ }^{-/-}$mice (Additional File 1 Figure S1). Surprisingly, skeletal muscle, lung, and kidney also exhibited significant decreases in the $I L-6$ mRNA expression compared to WT counterparts, while brain, bone marrow cells and mesenteric lymph nodes had no difference. The organs with significantly increased levels of $I L-6$ mRNA in Ceacam $1^{-/-}$mice in comparison with WT mice were liver and spleen (Fig. 3a). Given the large size of the liver, the tentative conclusion was that liver may be the main IL-6 producer in response to i.p. LPS, followed by the spleen.
However, blood cells were not removed prior to this analysis.

Liver cells and splenocytes are not the source of IL- 6 in early response to LPS

To further explore the role of liver and spleen in the secretion of IL-6 in response to LPS, liver cells (from PBS perfused liver to remove blood cells) and splenocytes from untreated mice to determine which cells, if any, produce IL-6 in direct response to LPS in vitro. Our results showed that IL-6 mRNA expression of liver cells and splenocytes after treatment with LPS for $2 \mathrm{~h}$ were 
A
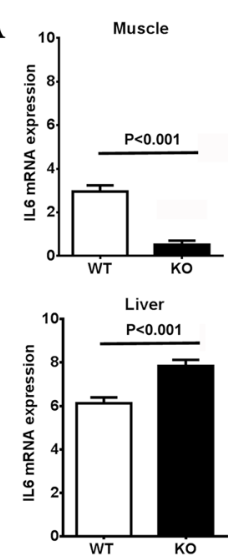

B

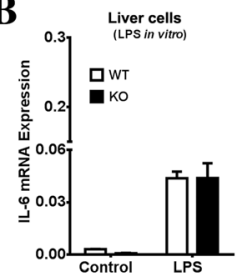

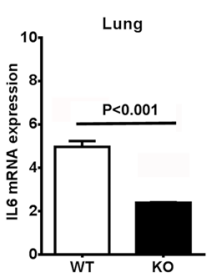
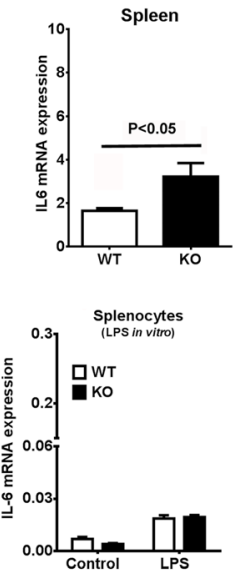
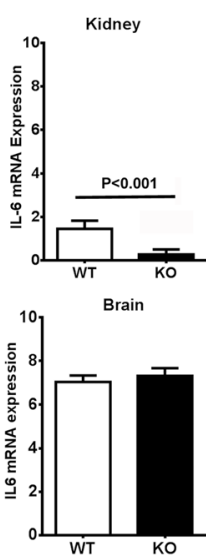

C

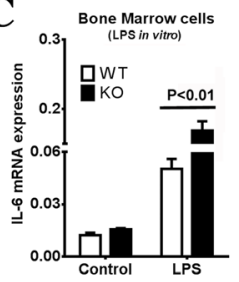

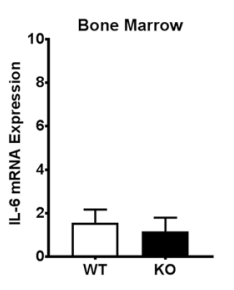

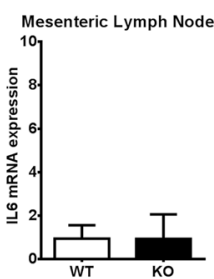

D

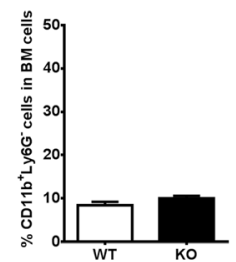

\section{E}
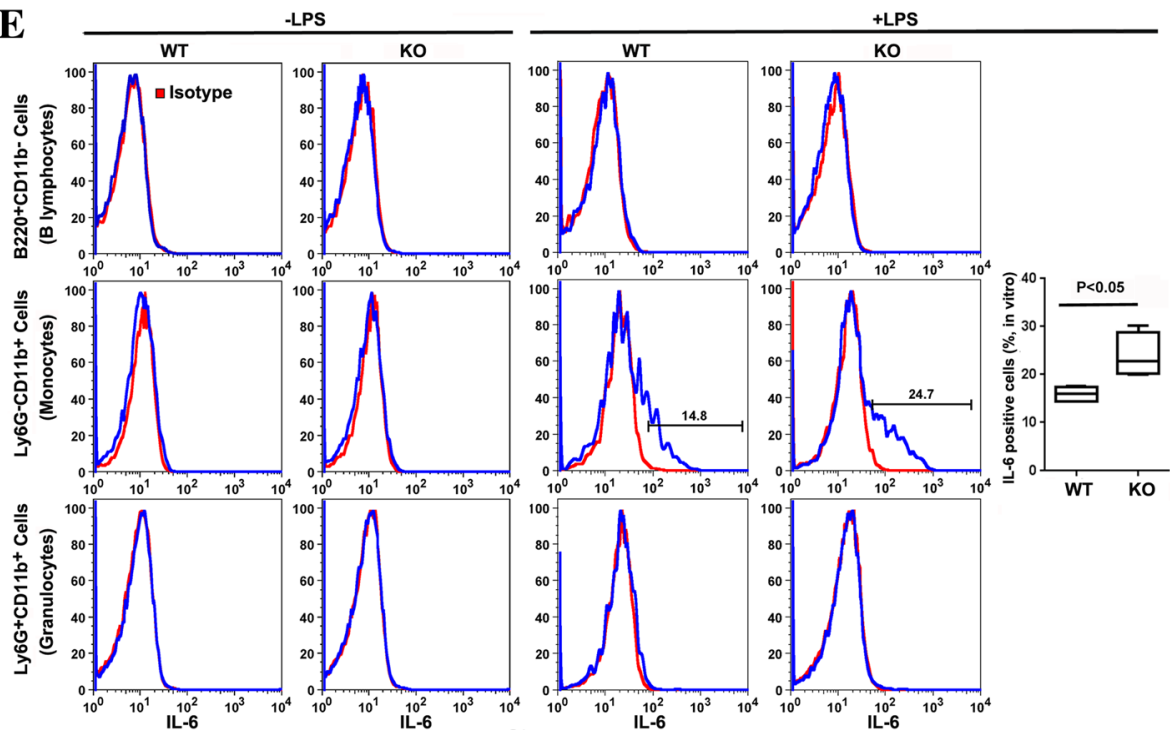

F
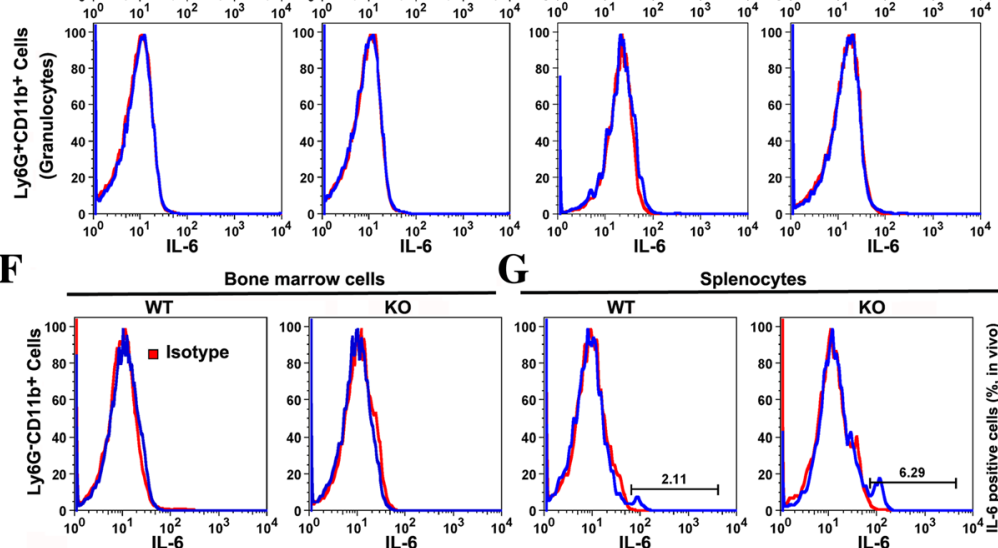

G

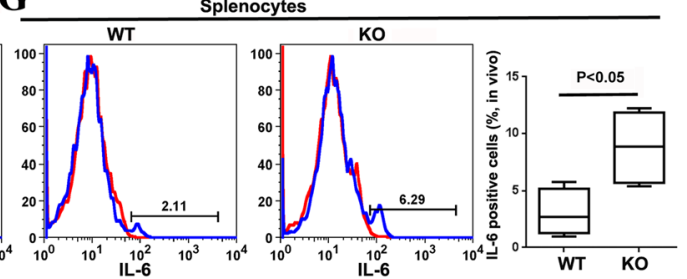

Fig. 3 IL-6 expression levels of organs in Ceacam $1^{-1-}$ mice in response to LPS challenge. (a) IL-6 mRNA expression levels of mouse organs after i.p. injection of LPS $(10 \mathrm{mg} / \mathrm{kg})$ for $2 \mathrm{~h}(n=4)$. (B) $/ \mathrm{L}-6 \mathrm{mRNA}$ expression level in PBS perfused liver and splenocytes after treated with $500 \mathrm{ng} / \mathrm{mL}$ LPS for $2 \mathrm{~h}$ in vitro $(n=3)$. (c) IL-6 mRNA expression level in bone marrow cells after treated with $500 \mathrm{ng} / \mathrm{mL}$ LPS for $2 \mathrm{~h}$ in vitro ( $n=3$ ). (d) Percentage of bone marrow CD1 1 b ${ }^{+} \mathrm{Ly}_{6 \mathrm{G}}{ }^{-}$cells in WT and Ceacam ${ }^{-1-}$ mice $(n=4)$. (e) Intracellular staining of IL-6 in bone marrow cells after treated with Brefeldin A (BFA) plus $500 \mathrm{ng} / \mathrm{mL}$ LPS for $5 \mathrm{~h}$ in vitro $(n=3)$. (f) Intracellular staining of IL-6 of bone marrow cells after i.p. injection of BFA plus LPS (10 mg/kg) for $5 \mathrm{~h}$ in vivo $(n=3)$. (g) Intracellular staining of IL-6 of splenocytes after i.p. injection of BFA plus LPS $(10 \mathrm{mg} / \mathrm{kg})$ for $5 \mathrm{~h}$ in vivo $(n=3)$ 
not different between WT and Ceacam1 ${ }^{-/-}$mice (Fig. $3 \mathrm{~b})$. When isolated hepatocytes or Kupffer cells were treated with LPS plus BFA (brefeldin A) for $5 \mathrm{~h}$, hepatocytes from Ceacam1 ${ }^{-/-}$mice were negative for both IL-6 and TNF $\alpha$ (Additional File 1 Figure S2A) while Kupffer cells were positive for TNF $\alpha$ only (Additional File 1 Figure S2B). Furthermore, the IL-6 secretion of liver cells in response to LPS treatment was not significantly different between the two mouse strains until after $6 \mathrm{~h}$ (Additional File 1 Figure S3A).

Based on these results, we concluded that the IL- 6 production observed for the liver (Fig. 3a) was due to trapped blood cells at the time of euthanasia. Therefore, the analysis was repeated on liver perfused after i.p. LPS treatment. There were no differences in $I L-6$ mRNA levels between WT and Ceacam1 ${ }^{-/-}$mice (data not shown), suggesting that blood cells trapped in the liver, rather than endogenous cells were responsible for the observed difference (Fig. 3a). Western blot analysis of phospho-gp130, the key activation signal transducer of the IL- 6 receptor, revealed that livers of both WT and Ceacam1 ${ }^{-/-}$mice had similar levels after LPS treatment (Additional File 1 Figure. S3B). The same was true for the downstream effectors of the gp-130, pSTAT1, pSTAT3 and SOCS3 (Additional File 1 Figure. S3B). We conclude that although the liver is a major organ responsive to IL-6, it is not the main source of IL-6 in the early response to LPS.

\section{A subgroup of bone marrow $\mathrm{CD} 11 \mathrm{~b}^{+} \mathrm{Ly}_{6 \mathrm{G}}{ }^{-}$myeloid cells secrete IL- 6 and are mobilized in the early response to LPS}

Since it was likely that the source of the IL- 6 producing cells in the liver and spleen originated from the bone marrow, we collected bone marrow cells from untreated mice and determined their in vitro production of IL-6 in response to LPS. This analysis revealed significantly higher levels of $I L-6$ mRNA for Ceacam1 ${ }^{-/}$vs WT bone marrow cells in response to LPS (Fig. 3c).

Analysis of cell surface markers of bone marrow cells together with intracellular IL-6 staining after LPS treatment revealed that a subgroup of $\mathrm{CD} 11 \mathrm{~b}^{+} \mathrm{Ly} 6 \mathrm{G}^{-}$cells but not $\mathrm{CD} 11 \mathrm{~b}^{+} \mathrm{Ly}_{6 \mathrm{G}^{+}}$cells (granulocytes) or $\mathrm{B} 220^{+}$cells (B lymphocytes) produced IL-6 (Fig. 3e). Notably, there was no significant difference in $\mathrm{CD} 11 \mathrm{~b}^{+} \mathrm{Ly} 6 \mathrm{G}^{-}$cell percentages of bone marrow cells between WT and Ceacam $1^{-1-}$ mice (Fig. 3d), suggesting that the number of IL-6 producing cells in the bone marrow per se are not responsible for the IL-6 differences observed between WT and Ceacam1 $1^{-/-}$ mice. In accordance with the negative finding of $I L-6$ mRNA in bone marrow cells treated with LPS in vivo (Fig. 3a), intracellular staining of IL-6 was negative in bone marrow cells after i.p. injection of LPS plus BFA (Fig. 3f), but positive in one subgroup of $\mathrm{CD} 11 \mathrm{~b}^{+} \mathrm{Ly}_{6 \mathrm{G}}{ }^{-}$cells in the spleen (Fig. 3g). These results suggest that IL-6 producing bone marrow cells were mobilized from the bone marrow to the spleen after i.p. LPS treatment and that the subgroup of CD11b ${ }^{+}$Ly6G $G^{-}$cells may be responsible for the difference of IL-6 production between WT and Cea$\mathrm{caml}^{-/-}$mice after LPS challenge.

\section{Monocytes and the progenitors of myeloid CD11 $\mathrm{b}^{+} \mathrm{Ly} 6 \mathrm{G}^{-}$} cells are IL-6 producing cells in the early response to LPS Since $\mathrm{CD} 11 \mathrm{~b}^{+} \mathrm{Ly}_{6 \mathrm{G}^{-}}$cells in the bone marrow include different groups of myeloid cells, further analysis of cell surface markers was performed to clarify which cell type was responsible for IL-6 production. Recent studies have divided bone marrow CD115 (M-CSF-R) positive cells into monocytes (Mo), common monocyte progenitors (cMoP), monocyte-macrophage DC progenitors (MDP) and common DC precursor (CDP) according to cell surface markers CD117 (c-Kit) and CD135 (FLT-3) [45]. Cell surface staining showed that all of four populations are CEACAM1 positive in WT mice (Additional File 1 Figure. S4A).

After in vitro treatment of bone marrow cells with LPS, CD115 expression was down-regulated while the staining patterns of MDP, cMoP, Mo and CDP were indistinguishable (Additional File 1 Figure. S4B). Therefore, the four populations of MDPs $\left(\mathrm{Lin}^{-} \mathrm{CD} 115^{+} \mathrm{CD} 117^{+} \mathrm{CD} 135^{+}\right)$, cMoP $\left(\mathrm{Lin}^{-} \mathrm{CD} 115^{+} \mathrm{CD} 117^{+} \mathrm{CD} 135^{-}\right)$, Mo $\left(\mathrm{Lin}^{-} \mathrm{CD} 115^{+} \mathrm{CD} 117^{-} \mathrm{C}\right.$ $\left.\mathrm{D} 135^{-}\right)$, and $\mathrm{CDP}\left(\mathrm{Lin}^{-} \mathrm{CD} 115^{+} \mathrm{CD} 117^{-} \mathrm{CD} 135^{+}\right)$were sorted (Fig. 4a) and treated with LPS plus BFA for $5 \mathrm{~h}$. In WT mice, cMoP and Mo but not MDP and CDP were IL-6 positive. Surprisingly, in Ceacam1 $1^{-1-}$ mice, $\mathrm{cMoP}$, Mo, and MDP but not CDP were all positive for IL- 6 with significantly increased percentages over WT (Fig. 4e-f). There were no significant differences in the percentages of $\mathrm{Lin}^{-}$ cells (Fig. 4b), CD115 ${ }^{+}$cells (Fig. 4c), nor the MDP, cMoP, Mo, and CDP subsets between WT and Ceacam1 ${ }^{-1-}$ mice (Fig. 4d). These analyses show that monocytes and their progenitors are the major IL-6 producing cells in the bone marrow in the early response to LPS, and that the absence of CEACAM1 results in high levels of IL-6 production.

\section{Macrophages do not produce IL- 6 in the early response to LPS}

Since monocytes and macrophages differ in their ability to process pro-IL- $1 \beta$ and release mature IL-1 $\beta[46,47]$, it was necessary to determine if a similar situation occurred for IL-6 production and secretion in macrophages. Peritoneal cavity macrophages, isolated from WT and Ceacam $1^{-/-}$mice, were treated in vitro with LPS for 2,4 and $24 \mathrm{~h}$. The results showed no difference in $I L-6$ mRNA levels between WT and Ceacam1 ${ }^{-/}$mice at the $2 \mathrm{~h}$ time point, but $I L-6$ mRNA levels significantly increased at the 4 $\mathrm{h}$ time point and decreased at the $24 \mathrm{~h}$ time point in Ceacam1 $1^{-/}$mice (Additional File 1 Figure S5A). It should be noted that WT peritoneal cells produced a robust TNF $\alpha$ response to LPS compared to a much weaker IL6 response at 

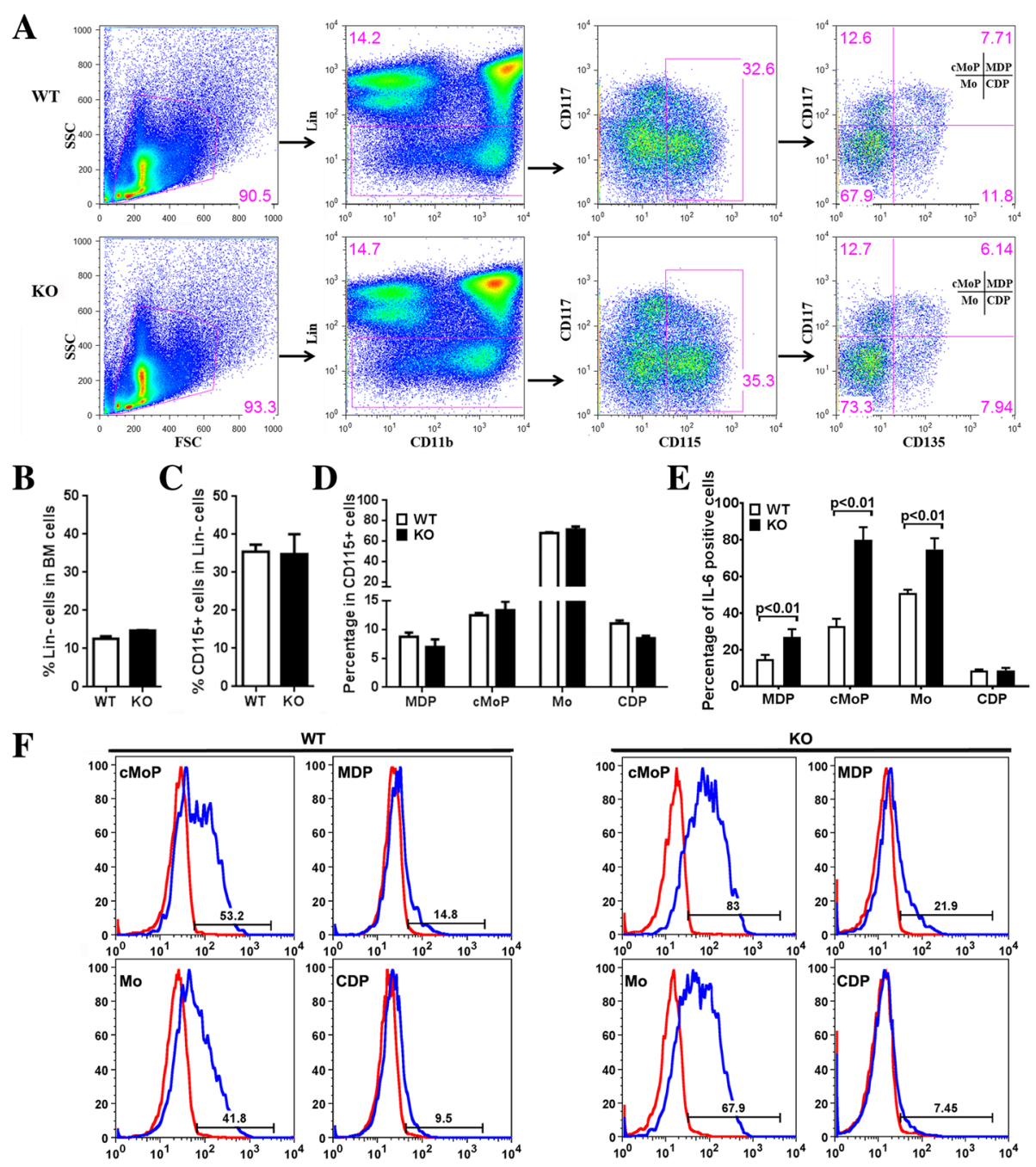

Fig. 4 Production of IL-6 in monocytes and their progenitors in wild type and Ceacam $1^{-1-}$ mice. (a) Flow cytometry gating of monocytes (Mo), common monocyte progenitors (CMoP), monocyte-macrophage DC progenitors (MDP) and common DC precursors (CDP) in bone marrow cells $(n=4)$. (b) Percentage of Lin ${ }^{-}$cells in bone marrow cells $(n=4)$. (Note: Lin = lineage markers: including CD3, CD19, B220, Ly6G, NK1.1, TER119) (c) Percentage of $C D 115^{+}$cells in Lin bone marrow cells $(n=4)$. (d) Percentage of MDP, cMoP, Mo, and CDP in $\operatorname{Lin}^{-} \mathrm{CD} 115^{+}$bone marrow cells $(n=$ 4). (e) Percentage of intracellular IL-6 staining in sorted MDP, CMoP, Mo, and CDP cells after treatment with Brefeldin A (BFA) plus $500 \mathrm{ng} / \mathrm{mL}$ LPS for $5 \mathrm{~h}$ in vitro $(\mathrm{n}=4)$. (F) Flow analysis of intracellular IL-6 staining of sorted MDP, CMoP, Mo, and CDP cells after treatment with BFA plus $500 \mathrm{ng} /$ $\mathrm{mL}$ LPS for $5 \mathrm{~h}$ in vitro $(\mathrm{n}=4)$

$2 \mathrm{~h}$. The blunted TNFa response from Ceacam1 ${ }^{-/-}$peritoneal cells, while interesting, was not a studied further, given our emphasis on the role of IL6 in fever production. When splenocytes from Ceacam1 ${ }^{-/-}$mice were treated with LPS plus BFA for $5 \mathrm{~h}$, all three groups of myeloid cells (Ly6 $\mathrm{G}^{-} \mathrm{CD} 11 \mathrm{~b}^{+}$cells), granulocytes (Ly6G ${ }^{+} \mathrm{CD} 11 \mathrm{~b}^{+}$cells), and lymphocytes ( $\mathrm{Ly}_{6 \mathrm{G}^{-}} \mathrm{CD} 11 \mathrm{~b}^{-}$cells) were negative for IL-6 by intracellular staining (Additional File 1 Figure. S5B). Similar results were obtained for WT mice (data not shown). Furthermore, the murine macrophage cell line RAW264.7 treated with LPS plus BFA for $5 \mathrm{~h}$ was negative for intracellular IL-6 production (Additional File 1 Figure. S5C). In fact, RAW264.7 cells treated with LPS showed that
$T N F \alpha$ rather than $I L-6$ mRNA significantly increased at $2 \mathrm{~h}$ in comparison with untreated controls, and that $I L-6$ mRNA levels only started to increase at the $4 \mathrm{~h}$ time point, maintaining the increase through the $24 \mathrm{~h}$ time point (Additional File 1 Figure S5D). The release of IL-6 into the supernatant after LPS treatment was delayed until the $24 \mathrm{~h}$ time point but not at the early $2 \mathrm{~h}$ time point (Additional File 1 Figure S5E). Intracellular IL-6 staining analysis showed that these cells began to produce IL-6 only after 11 $\mathrm{h}$ of LPS treatment (Additional File 1 Figure S6A). Furthermore, silencing of CEACAM1 with siRNA in RAW264.7 cells did not affect IL-6 secretion at the $2 \mathrm{~h}$ time point (Additional File 1 Figure S6B). Another murine 
macrophage cell line, J774A.1, exhibited similar results as RAW264.7 cells, i.e., there was no IL-6 production within $5 \mathrm{~h}$ after LPS treatment and CEACAM1 siRNA did not interfere with IL-6 production (Additional File 1 Figure S7). Moreover, Kupffer cells in the liver (analyzed above, Additional File 1 Figure S2B) gave similar results as did spleen macrophages (Additional File 1 Figure S5B). These data indicate that although macrophages are derived from either monocytes or the yolk sac, and are self-replenished [48], they are unable to synthesize and release IL- 6 in the early phase $(<2 \mathrm{~h})$ of the LPS response.

To further explore the early response to LPS treatment, the time course of $I L-6$ mRNA was measured in bone marrow monocytes. As shown in Fig. 5a, IL-6 mRNA is significantly increased as early as $30 \mathrm{~min}$ after LPS treatment and reached a peak at $90 \mathrm{~min}$ in Ceacam1 ${ }^{-1-}$ mice. These data confirm that monocytes are the main source of IL-6 in the early response to LPS and that CEACAM1 regulates this response. Given the reports that LPS induced IL- 6 itself leads to a further increase in IL-6 production $[49,50]$, Il6ra ${ }^{-1-}$ mice and Stat $3^{\text {floxfflox }}$ mice were included in our study. The analysis of $I L-6$ mRNA expression of bone marrow monocytes from Il6ra ${ }^{-1-}$ mice (Fig. 5a) and Stat $f^{f l o x} / f l o x$ mice (Fig. 5b) demonstrated a different expression pattern compared to the Ceacam1 ${ }^{-1-}$ mice over the time course of LPS treatment. These results suggest CEACAM1 expression does not interfere with the IL-6 receptor signaling pathway, but only in the production of IL-6.

\section{TLR4 is not expressed on murine bone marrow monocytes}

Having identified bone marrow monocytes as the source of prompt IL-6 secretion in response to LPS, we proceded to analyze the mechanism of CEACAM1 regulation. Since our previous studies showed CEACAM1 regulated TLR4 signaling in murine neutrophils, we expected a similar mechanism in murine monocytes, especially since human monocytes express abundant amounts of TLR4 [26]. TLR4, the canonical LPS receptor, signals through the MyD88and Toll/IL-1R domain-containing adapter inducing IFN- $\beta$ (TRIF)-dependent upstream signals that lead to the production of proinflammatory (IL-6 and IL-1 $\beta$ ) and antiinflammatory mediators (IFN- $\beta$, IFN- $\alpha$, CCL5), respectively $[51,52]$. However, unlike IL-6 mRNA production in LPS treated murine monocytes, there was no change in the levels of IFN- $\beta, I F N-\alpha$, and CCL5 mRNA at the $30 \mathrm{~min}$ time point in WT, Ceacami ${ }^{-1-}$, and Il6ra ${ }^{-1-}$ mice. IFN- $\beta$, IFN- $\alpha$, and CCL5 mRNA levels began to increase after 60 min but did not exhibit differences between WT and Cea$\mathrm{caml}^{-/-}$mice at both the 60 and $90 \mathrm{~min}$ time points. These results suggests that the TRIF-dependent signaling pathway, as one of two main signaling pathways of TLR4, was not directly involved in the response of murine bone marrow monocytes to LPS. Furthermore, TLR4 expression was negative on bone marrow monocytes from both WT and Ceacam1 $1^{-/-}$mice using anti-TLR4 antibody surface staining (Fig. 5c) and western blot analysis (Fig. 5d) even though TLR4 mRNA was detected at low levels by qPCR (Fig. 5e). When RAW264.7 macrophage lineage cells were used as a positive control, TLR4 was easily detected by both surface staining and western blot analysis. On the other hand, CD14 that acts as an LPS co-receptor for TLR4, was strongly positive for bone marrow monocytes (Fig. 5c), suggesting the presence of an alternative LPS receptor. We also performed intracellular immunofluorescent staining to explore the possibility that TLR4 was localized to intracellular granules, but the monocytes were negative (data not shown). In addition, TLR4 blocking antibody and the TLR4 inhibitor C34 did not interfere with LPS-induced IL-6 mRNA expression in these cells treated with LPS (Fig. 5f). Taken together, we conclude that TLR4 is not expressed on murine bone marrow monocytes and that TLR4 signaling is not responsible for the observed IL-6 production of murine monocytes.

\section{RP105 (CD180) on bone marrow monocytes is the LPS receptor responsible for the early IL-6 response to LPS}

In consideration of alternative receptors for LPS, it is well known that B-cells respond strongly to LPS [53]. B-cells have two distinct LPS receptor complexes, TLR4/ MD2 and RP105/MD1 [54]. The extracellular domains of TLR4 and RP105 associate with MD2 and MD1, respectively, to form heterodimers, thereby forming the binding sites to LPS $[54,55]$. Although we did not detect TLR4 on murine monocytes, RP105 and MD1 were highly expressed on bone marrow monocytes from both WT and Ceacam1 ${ }^{-/-}$mice (Fig. 5C). Since the signaling pathway for RP105 has been extensively studied and involves recruitment of VAV1 and $\beta$-actin $[54,56]$, we performed a number of co-IP studies on murine bone marrow monocytes treated with LPS. MD1 co-IPed with RP105 in the presence or absence of LPS in bone marrow monocytes (Fig. 6a), while RP105 co-IPed with pVAV1 and $\beta$-actin in the absence of LPS in WT and Ceacam1 $1^{-/-}$mice (Fig. 6b). After treatment with LPS, pVAV1 and $\beta$-actin dissociated with RP105 in WT mice, but in Ceacam1 $1^{-1-}$ mice, pVAV1 and $\beta$-actin remained associated with RP105. IP of CEACAM1 in WT mice co-IPed $\beta$-actin after LPS treatment (Fig. 6c). These results suggest that CEACAM1 can sequester pVAV1 and $\beta$-actin from RP105 after LPS treatment thus negatively regulating RP105 downstream signaling. In the absence of CEACAM1, RP105 remains associated with pVAV1 and $\beta$-actin resulting in increased downstream signaling. Furthermore, the VAV1 inhibitor azathioprine, and a metabolite of azathioprine, 6-thio-GTP, were able to block the IL-6 mRNA over-response to LPS in Ceacam $1^{-/-}$mice (Fig. 6d). Moreover, an RP105 activating monoclonal 

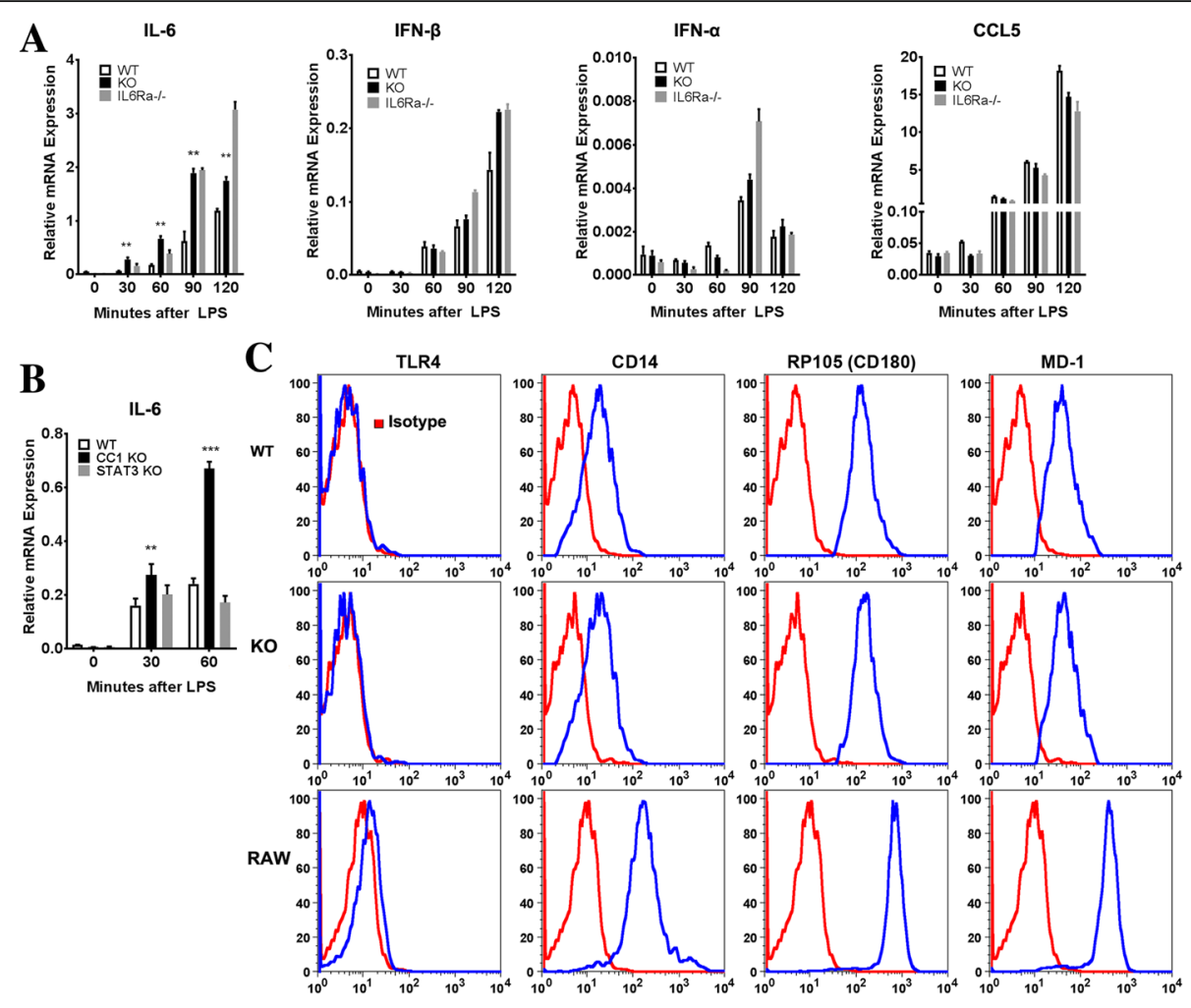

D

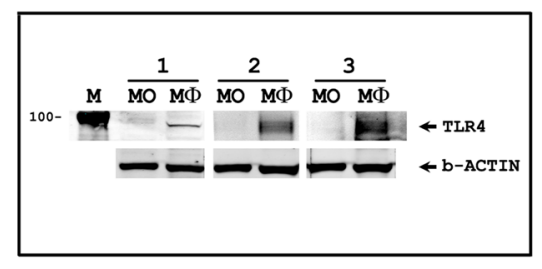

E

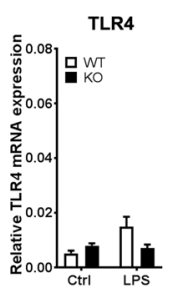

$\mathbf{F}$

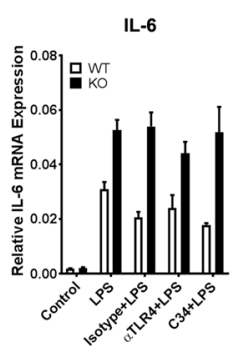

Fig. 5 Cytokine expression of bone marrow monocytes. Expression of RP105 but not TLR4. (a) IL-6, IFN- $\beta$, IFN- $a$ and CCL5 mRNA expression levels of bone marrow monocytes in WT, Ceacam $1^{-1-}$ and $\| 6 \mathrm{ra}^{-1-}$ mice after treatment of $500 \mathrm{ng} / \mathrm{mL}$ LPS in vitro $(\mathrm{n}=3)$. (b) $/ \mathrm{L}-6 \mathrm{mRNA}$ expression levels of bone marrow monocytes in WT, Ceacam $1^{-1-}$ and Stat $3^{\text {flox fllox }}\left(\right.$ Stat $^{-1-}$ ) mice after treatment of $500 \mathrm{ng} / \mathrm{mL}$ LPS in vitro $(n=3)$. (c) Surface TLR4, CD14, RP105 and MD1 staining of RAW264.7 cells and bone marrow monocytes of WT and Ceacam $1^{-/-}$mice $(n=3)$. (d) Immunoblot analysis for TLR4 detection in RAW264.7 cells and bone marrow monocytes of WT mice (1, 2, 3 mean three separated experiments; MO: monocytes; M 4 : RAW264.7 macrophages). (e) TLR4 mRNA expression level in bone marrow monocytes of WT and Ceacam ${ }^{-1-}$ mice $(\mathrm{n}=4)$. (f) IL-6 mRNA

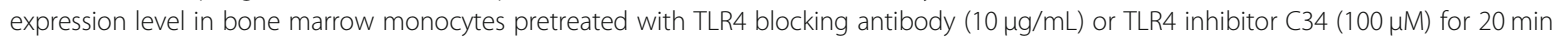
following $500 \mathrm{ng} / \mathrm{mL}$ LPS treatment for $30 \mathrm{~min}$ in vitro $(n=3)$

antibody [57] was able to stimulate IL-6 mRNA expression in WT mice and IL-6 mRNA over-expression in Cea$\mathrm{caml}^{-/-}$mice similar to LPS treatment (Fig. 6e). On the other hand, blocking antibodies to MD1 or CD14 completely abrogated LPS-induced IL- 6 mRNA expression in both WT and Ceacam1 ${ }^{-1-}$ mice (Fig. 6f). Furthermore, CD14 was co-IPed with RP105 (Fig. 6g). We conclude that the RP105/MD1/CD14 complex on murine bone marrow monocytes is responsible for the early phase expression of IL-6 in LPS treated mice, and CEACAM1 negatively regulates RP105 signaling in response to LPS stimulation.
It was reported that Lyn phosphorylation and its kinase activity were involved in RP105 signaling in B cells [54]. In our study of mouse monocytes, when RP105 was IPed, we did not detect Lyn, but instead, we found RP105 co-IPed with Src (Fig. 6g). A selective and competitive dual site $\mathrm{Src}$ inhibitor (Src 11) was able to block the over-response of $I L-6$ mRNA expression to LPS in Ceacam1 ${ }^{-/}$mice (Fig. 6h). This suggests that Src, but not Lyn, is the kinase involved in RP105 mediated LPS signaling in murine monocytes. 


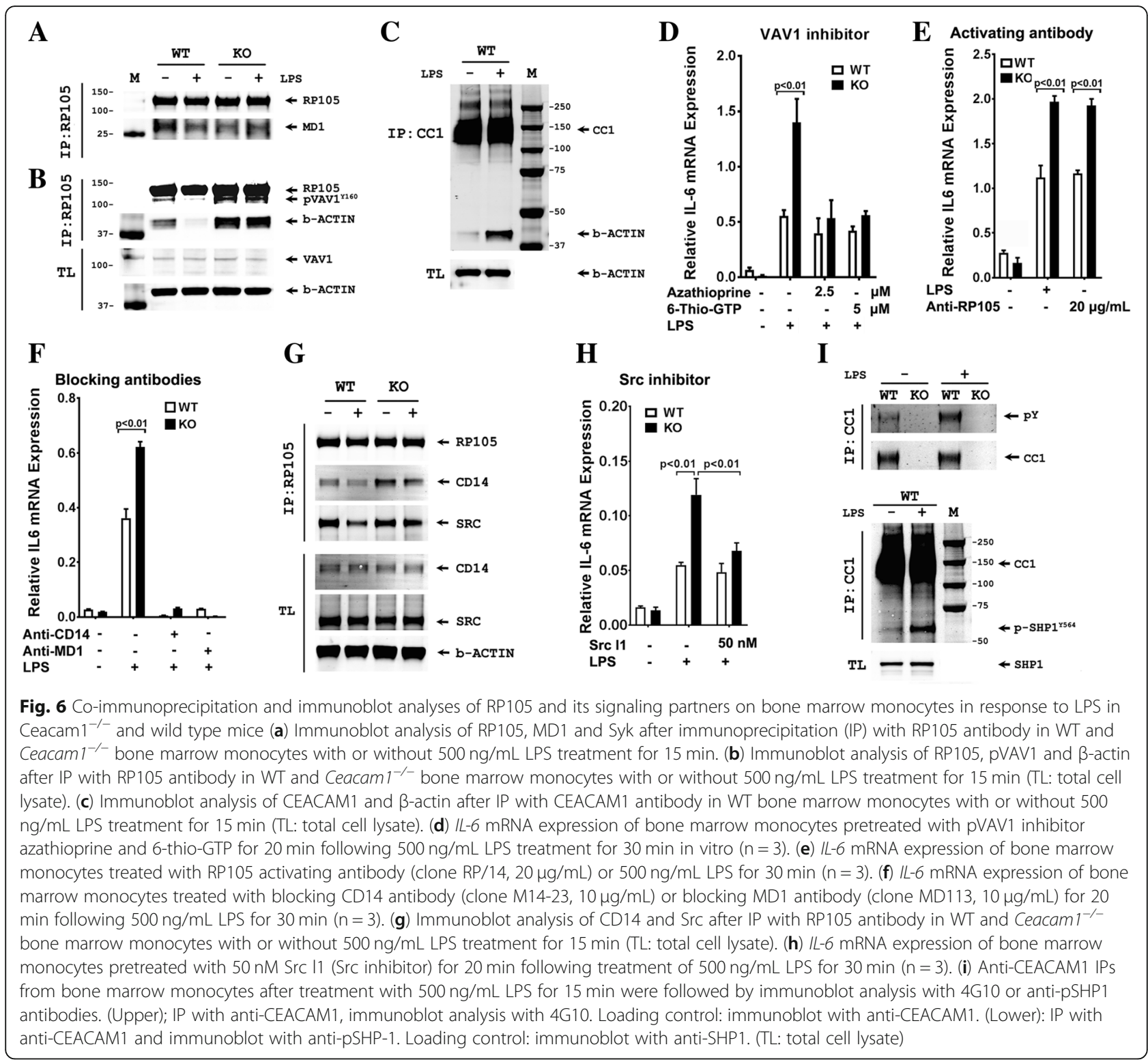

We have previously shown that CEACAM1 acts as an inhibitory B-cell co-receptor through recruitment of the inhibitory tyrosine phosphatase SHP-1 [16]. Suspecting a similar inhibitory mechanism in LPS treated monocytes, we IPed CEACAM1 in LPS treated monocytes and performed western blot analysis with anti-phosphotyrosine and anti-phospho-SHP-1 antibodies (Fig. 6I). The results demonstrate that CEACAM1 is phosphorylated on tyrosine after LPS treatment (Fig. 6I upper), that phospho-SHP-1 is co-IPed with CEACAM1, and the levels of phospho-SHP1 increase after treatment with LPS (Fig. 6I lower). Furthermore, treatment of bone marrow monocytes with LPS in the presence of SHP1 inhibitor, PTP inhibitor III, increases phospho-VAV1 in WT but not in Ceacam1 ${ }^{-/}$mice (Additional File 1 Figure S8). These results show that RP105 stimulation by LPS leads to recruitment of SHP-1 to CEACAM1, a result that limits tyrosine phosphorylation of both VAV1 and RP105 by Src. Thus, murine monocytes may share a common signaling pathway with B-cells since they both express CEACAM1 and RP105.

\section{Discussion}

IL-6 is a soluble mediator with a pleiotropic effect on inflammation, immune response and hematopoiesis affecting vascular disease, lipid metabolism, insulin resistance, mitochondrial activities, the neuroendocrine system and neuropsychological behavior [58]. In this study, we focused on the role of CEACAM1 in the regulation of IL-6 production. Rather surprisingly, we found that bone marrow monocytes and not peripheral macrophages 
were responsible for the early IL-6 response to i.p. LPS. Although there was an increase of $I L-6$ mRNA expression in macrophages after $2 \mathrm{~h}$, secreted IL- 6 occurred much later and was likely due to the early production of TNF $\alpha$ by these cells. Moreover, the bone marrow monocytes responsible for IL-6 production as shown by in vitro analysis, were not detected in the bone marrow of mice treated in vivo with LPS, perhaps demonstrating their rapid mobilization to the periphery. For example, analysis of the liver of LPS treated mice revealed that the source of IL6 was in the blood rather than in isolated hepatocytes or Kupffer cells. In accordance with this finding, it was earlier reported that low concentrations of Toll-like receptor (TLR) ligands in the bloodstream drive CCR2-dependent emigration of monocytes from the bone marrow [59]. In other results, we found that the CCR2 ligand, CCL-2 was elevated in both WT mice and Ceacam1 ${ }^{-1-}$ mice treated with LPS, with the higher levels in Ceacam1 ${ }^{-/-}$mice (data not shown).

The discovery of TLR family proteins was particularly critical in showing the importance of innate immunity in the host defense against microbial infection. TLRs are characterized by extracellular leucine-rich repeat (LRR) motifs and intracellular Toll/interleukin 1 receptor (TIR) domains [52]. TLR4 is a well-known pathogen recognition receptor that plays a key role in the prototypical inflammatory stimulus to LPS [60]. LPS binding to TLR4 promotes signaling events via intracellular Toll/IL-1R signaling domains, that involve the primary recruitment of the Mal adaptor protein and its subsequent association with My88 promoting the activation of the NF- $\mathrm{kB}$ transcriptional complex and induction of many pro-inflammatory cytokine genes, such as $I L-6, T N F \alpha$, and $I L-1 \beta$. TLR4 immune responses involve activation of signaling adaptors TRIF and TRIF-related adaptor molecules, that also facilitate activation of NF-KB and IRF3 (IFN regulatory factor 3), the latter of which promotes the transcription of proinflammatory type I IFN genes [61]. Unexpectedly, our results demonstrated that TLR4 protein is not expressed on murine bone marrow monocytes as evidenced by lack of activation of the TRIF-dependent pathway, absence of TLR4 protein and lack of effect on IL6 production by a TLR4 blocking antibody or TLR4 inhibitor C34. Although it is well known that TLR expression is high on human monocytes, many murine cells of myeloid origin, including macrophages, microglia, myeloid DCs, and granulocytes have been reported to have high levels of TLR4 expression [62]. However, the status of TLR4 expression in murine monocytes, neither TLR4 mRNA nor TLR4 protein was shown [63]. In contrast, mouse macrophages, as well as the two macrophage cell lines RAW264.7 and J774A.1, express TLR4 on their cell surface. However, neither of these cell lines, nor peripheral murine macrophages, exhibited an early IL-6 response to LPS $(<2 \mathrm{~h})$. Thus, most studies on LPS stimulated TLR signaling in the mouse are limited to macrophages, while in human, both monocytes and macrophages are used. A further source of confusion, relevant to our study is that mouse monocytes are CEACAM1 ${ }^{+}$and TLR4- (our data) while human monocytes are CEACAM1 ${ }^{-}$ and TLR4 ${ }^{+}$(Additional File 1 Figure S9). Notably, when we generated a human Ceacam1 transgenic (TG) mouse using the complete human CEACAM1 genome [64] and crossed them into the Ceacam1 ${ }^{-/-}$background, bone marrow monocytes in the hCeacam1 TG mice did not express hCEACAM1 protein (data not shown).

The finding that TLR4 negative murine bone marrow monocytes were responsible for the prompt IL6 response to LPS necessitated a search for an alternative LPS receptor. The obvious candidate, RP105, was first reported in 1995 as a LRR protein expressed on B cells [65]. Although RP105 has only 11 amino acids in the intracellular portion and lacks a TIR domain, ligation of RP105 with anti-RP105 monoclonal antibody (mAb) transmits powerful activation signals in B cells, including proliferation [66]. RP105 shares some features with TLR4. First, RP105 is associated with MD-1, an MD-2 homolog. Second, both RP105 and TLR4 contain 22 LRRs in their extracellular portions, suggesting the possible involvement of RP105/MD-1 in the LPS-induced response. In fact, RP105-deficient mice as well as MD-1-deficient mice show reduced LPS-dependent proliferation and CD86 up-regulation in B cells, albeit to a lesser extent than TLR4-deficient mice. Third, although LPS appears to bind to MD-1 with lower affinity than to MD-2 [67], the RP105/MD-1 complex is expressed not only on B cells but also on macrophages and dendritic cells [68]. We now report that the RP105/MD1 complex is also expressed on murine bone marrow monocytes and is negatively regulated by CEACAM1 as evidenced by sequestrating pVAV1 and $\beta$-actin from pRP105 in WT mice and the increased association of RP105 with pVAV1 and $\beta$-actin in CEACAM1 ${ }^{-/-}$mice. The involvement of pVAV1 and $\beta$-actin in LPS stimulated RP105 signaling in B-cells has been previously reported [55]. Furthermore, we show that CEACAM1 in murine monocytes is phosphorylated on tyrosine and recruits the inhibitory tyrosine phosphatase SHP1 after treatment of with LPS, a finding similar to our previous studies on murine neutrophils treated with LPS [12]. More importantly, CEACAM1, itself an actin recruiting receptor [69], competes with VAV1 for actin recruitment, thus diminishing the ability of VAV1 to signal downstream to mediators such as NFkB, required for IL-6 expression. The dramatic sequestration of actin away from VAV1 is shown in Fig. 6c. The overall model for LPS/RP105 signaling in murine monocytes in shown in Fig. 7.

It is well-known that macrophages and dendritic cells are monocyte-differentiated cells that express both TLR4/ 
MD2 and RP105/MD1. In agreement with our finding that macrophages are more tuned to LPS/TLR4 signaling, it was shown that macrophages lacking RP105- or MD-1 made TNF $\alpha$ in response to LPS [68]. While DCs from RP105-deficient mice produced significantly higher concentrations of proinflammatory cytokines after stimulation with LPS, the RP105/MD-1 complex competes with the binding of LPS to the TLR4-MD-1 complex and negatively regulate LPS-TLR4-mediated responses in dendritic cells [70]. If TLR4 is a high affinity receptor for LPS while RP105 a low affinity receptor, the differential expression between macrophages/dendritic cells and murine bone marrow monocytes may be a fine-tuning mechanism to prevent an over-response to LPS, in this case, initiation of the fever response. Moreover, peripheral blood monocytes, acting as adult stem cells, are capable of undergoing maturation into several types of tissue-resident macrophages, including tissue resident macrophages, Kupffer cells, Langerhans cells of the skin, dendritic cells, microglia, and osteoclasts [71]. In the process of their tissue differentiation their requirement for sensitivity to LPS may change.

A major finding of our study is that CEACAM1, previously shown to regulate LPS signaling in neutrophils, also regulates LPS signaling in monocytes, but in the case of neutrophils the inhibitory regulation is through TLR4 [12], while in monocytes through RP105. In both cases, recruitment of the inhibitory tyrosine phosphatase SHP1 is involved, suggesting that the ITIM sequence in CEACAM1 [12] plays a major role in dampening

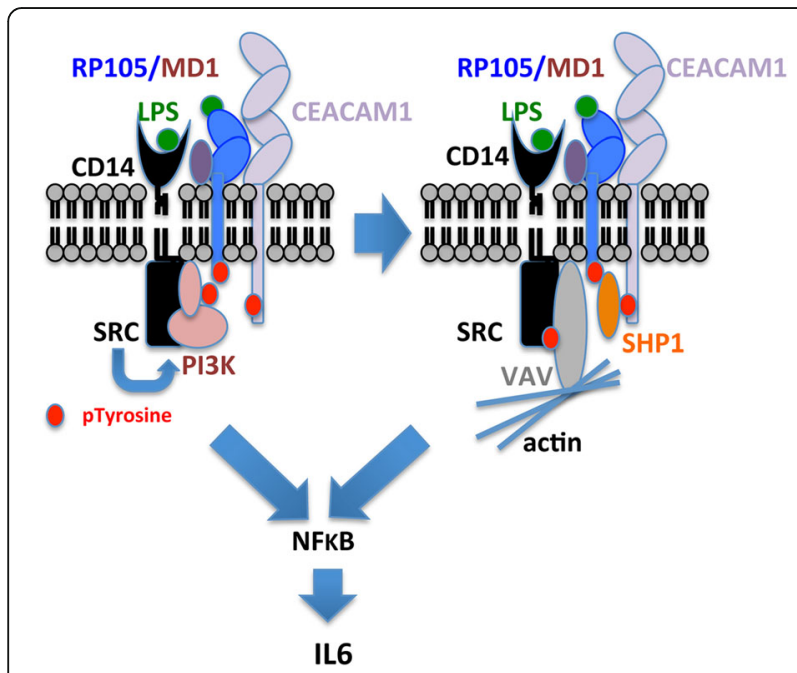

Fig. 7 Model for regulation of RP105 signaling in LPS treated murine monocytes. RP105 (blue) associates with MD1 (purple) and CD14 (black). In response to LPS, the complex recruits SRC (black), VAV1 (grey), actin (It. blue) and CEACAM1 (mauve). SRC phosphorylates tyrosines (red) on RP105, VAV1, and CEACAM1. SHP1 (orange) is recruited to the PITIM on CEACAM1, and in turn, is phosphorylated on its tyrosine by SRC. Downstream signaling of VAV1, dependent on recruitment of actin, is reduced by sequestration of actin by CECAM1 (shown by arrows) immune responses in a wide variety of immune cells. Indeed, that is also the case for B-cells [16] and T-cells [19]. A second major finding of our study is that the prompt secretion of IL6 in response to LPS occurs through $\mathrm{BM}$ monocytes in the mouse and that it is negatively regulated by CEACAM1. Indeed, CEACAM1 ${ }^{-/-}$ mice experience hyper IL6 responses to LPS, included exaggerated surface temperature depression (the mice shiver and huddle together in their cages) and overt diarrhea in about $50 \%$ of the treated animals. Not surprisingly, IL-1 $\beta$, the other key regulator in the fever response, is also regulated by CEACAM1 [12]. Thus, CEACAM1 plays an inhibitory role at two levels in the fever response, and may be a candidate drug target for fever reduction.

\section{Experimental procedures \\ Mice strains}

All mice were of the C56Bl/ 6 background. The method of euthanasia (asphyxiation by $\mathrm{CO}_{2}$ and cessation of breathing) is an approved AVMA method of euthanasia. Ceacam1-/- mice were generated by Nicole Beauchemin and coworkers (McGill University, Montreal, Canada). WT C57/B6 mice were purchased from Jackson laboratory (Bar Harbor, ME). IL-6R $\alpha$ (CD126)-deficient $\left(\mathrm{Il}_{6 \mathrm{ra}}{ }^{-/-}\right)$mice and Stat $3^{\text {flox/flox }}$ mice were mentioned in the publication [72]. Mice 7-12 weeks old were used for all the experiments.

\section{Synthesis, radiolabeling and PET imaging of DOTH- conjugated LPS and synthesis of FAM-labeled LPS}

LPS (10 mg, O55:B5 E. coli, Sigma-Aldrich) was made monomeric by treatment with $5 \mathrm{ml}$ of $0.5 \%$ triethylamine (Sigma-Aldrich) and by sonication for $15 \mathrm{~min}$ on ice. After the sonication, $200 \mu \mathrm{l}$ of LPS was removed from the solution and added to a tube containing NaIO4 $(20 \mathrm{ul}, 20 \mathrm{mM}$, made freshly), pH 7.1. Excess NaIO4 was removed on a Zeba spin column (Thermo Scientific, IL.) after incubated $30 \mathrm{~min}$ on ice, reacted with $26 \mathrm{ul}$ of DOTH $(7.8 \mathrm{mM}$ in $\mathrm{H} 2 \mathrm{O}, 202 \mathrm{nmol}$ ), $\mathrm{pH} 6.2$, at RT for $2 \mathrm{~h}$., and then treated with $10 \mathrm{ul}$ of sodium cyanoborohydride $(200 \mathrm{mM}$ in $\mathrm{H} 2 \mathrm{O}$, $2000 \mathrm{nmol}$ ) at RT for $2 \mathrm{~h}$., followed by running a Zeba spin column again to remove excess DOTA and NaCNBH3. All reaction was protected from light [73]. Preparation of FAM-LPS follow the protocol of the FAM conjugation from company.

\section{Real time RT-PCR}

Total RNA was purified from cell pellets using Trizol reagent (Invitrogen) according to the manufacturer's instructions. The concentrations and purity of extracted RNA were measured using the NanoDrop ND-1000 Spectrophotometer (NanoDrop, Wilmington, DE) demonstrating RNA with high purity (260/280 absorbance ratio between 2.1-2.2). Using Omniscript Reverse Transcription Kit (Qiagen), $1 \mu \mathrm{g}$ of total 
RNA was used for the generation of cDNA as outlined by the manufacturer in a total volume of $20 \mu \mathrm{l}$. Following cDNA systhesis, $2 \mu \mathrm{l}$ was used in real time RT-PCR reactions performed on CFX96 Touch Real-Time PCR Detection System (Bio-Rad) in a $20 \mu \mathrm{l}$ volume with iQ $\mathrm{SYBR}^{\circ}$ Green Supermix (Bio-Rad), according to the manufacturer's instructions. Primers were applied to a final concentration of $10 \mathrm{uM}$. Primer sequences are as follows: IL-6 forward (5'TTCCATC CAGTTGCCTTCTTGG-3'), IL-6 reverse (5'-TTCTCATTT CCACGATTTCCCAG-3'); TNF $\alpha$ forward (5'-AGCACAGA AAGCATGATCCGC-3'), TNF $\alpha$ reverse (5'-TGCCACAAG CAGGAATGAGAAG-3'); GAPDH forward (5'-GTCGGTG TGAACGGATTTG-3'), GAPDH reverse (5'-GAACATGTA GACCATGTAGTTG-3'), TLR4 forward (5'-ATGGCATGG CTTACACCACC-3'), TLR4 reverse (5'-GAGGCCAATTTT GTCTCCACA-3'); IFN $\beta$ forward (5'-CAGCTCCAAGAAA GGACGAAC-3'), IFN $\beta$ reverse (5'-GGCAGTGTAACTCT TCTGCAT-3'); IFN $\alpha$ forward (5'-TGATGAGCTACTAC TGGTCAGC-3'), IFN $\alpha$ reverse (5'-GATCTCTTAGCACA AGGATGGC-3'); CCL5 forward (5'-GCTGCTTTGCCTAC CTCTCC-3'), CCL5 reverse (5'-TCGAGTGACAAACACG ACTGC-3'). A TaqMan probe (Mm00462535_g1) from Life Technologies was used for detection of Regnase1. After denaturation for $3 \mathrm{~min}$ at $95^{\circ} \mathrm{C}, 40$ cycles of amplification were performed $\left(95^{\circ} \mathrm{C}\right.$ for 10 s then $55^{\circ} \mathrm{C}$ for $\left.10 \mathrm{~s}\right)$. Finally, melting curves were generated between $55^{\circ} \mathrm{C}$ and $95^{\circ} \mathrm{C}$, for every $0.5^{\circ} \mathrm{C}$. All Ct values were normalized to GAPDH, and quantification of gene expression was calculated by using the $\triangle \mathrm{CT}$ method.

\section{Flow cytometry and cell sorting}

Bone marrow cells were flushed out using PBS with $2 \%$ FBS and red blood cells were lysed using red blood cell lysis buffer (Sigma-Aldrich). For cell surface staining, cells were washed with PBS, blocked with anti-mouse CD16/32 antibody, stained with antibodies described in the figures, washed 3 times with $1 \%$ BSA PBS, and analyzed with a FACSCanton II cytometer (BD Biosciences). For intracellular staining, after treated with Brefeldin A (BFA) and 500 $\mathrm{ng} / \mathrm{mL}$ LPS for $5 \mathrm{~h}$, cells were washed with PBS, fixed with Fixation/Permeabilization Concentrate/diluents (eBioscien ce, San Diego, USA), blocked with anti-mouse CD16/32 antibody, and stained with antibodies shown in the figures. After washed with PBS containing 1\% BSA and $0.1 \%$ saponin, stained cells were assessed with a FACSCanton II cytometer.

For cell sorting, total cells were stained with FITC conjugated lineage marker antibodies (anti-Ly-6G, anti-B220, anti-CD3, anti-Ter119, anti-NK1.1 and anti-CD19), and $\mathrm{PE} / \mathrm{Cy} 5$ conjugated anti-CD135, PE/Cy7 conjugated antiCD11b, APC conjugated anti-CD115, and APC/Cy7 conjugated anti-CD117 (Biolegend, San Diego, CA 92121) and sorted by SROP. Purity was checked using FACSCanton II and $>95 \%$ purity sorted cells were used in the experiment.

\section{Bone marrow monocyte isolation and cytokine cytometric} bead assay

Sorted bone marrow monocytes (Mo), common monocyte progenitors (cMoP), monocyte-macrophage DC progenitors (MDP) and common DC precursors (CDP) were cultured in the concentration of $1 \times 10^{6} / \mathrm{mL}$ with RPMI1640 supplement with 10\% FBS and antibiotics. For surface staining, cells were stained with TLR4-PE (Clone UT41) and Isotype-PE (Clone eBR2a) (eBiosciences) and TLR4-APC (Clone SA15-21), CD14-PE (Clone Sa14-2), RP105-PE (Clone RP/14), MD1-PE (Clone MD-113) and isotypes (Biolegend, San Diego, CA 92121). For intracellular IL-6 and TNF $\alpha$ analysis, cells were treated with BFA and $500 \mathrm{ng} / \mathrm{mL}$ LPS for $5 \mathrm{~h}$, then cells were analyzed using intracellular anti-IL-6-APC and anti-TNF $\alpha$-APC (Biolegend, San Diego, CA 92121) staining. For LPS treatment or RP105 antibody treatment, cells were treated with 500 $\mathrm{ng} / \mathrm{mL}$ LPS or $20 \mu \mathrm{g} / \mathrm{mL}$ anti-RP105 antibody (Clone RP/ 14 , Biolegend) over time shown in the figures and harvested for qPCR analysis. For blocking and inhibiting experiment, cells were incubated over time shown in the figures or preincubated with TLR4 blocking antibody (Clone 76B357.1, Novus, Littleton, CO80210, USA), VAV1 inhibitor Azathioprine and 6-thio-GTP (abcam, Cambridge, MA02139, USA), CD14 blocking antibody (Clone M14-23, Biolegend), MD1 blocking antibody (Clone MD113, abeomics, San diego, CA92121), SHP-1 inhibitor PTP inhibitor III (Cayman Chemical, Ann Arbor, Michigan), Src inhibitor Src I1 (Tocris, Minneapolis, MN55413, USA), TLR4 inhibitor C34 (Tocris, Minneapolis, MN55413, USA) for 20 min following treated with $500 \mathrm{ng} /$ $\mathrm{mL}$ LPS over time shown in the figures. Then, cells were harvested for qPCR or immunoblot analysis. For IL-6 release analysis, cells were treated with $500 \mathrm{ng} / \mathrm{mL}$ LPS over time in the figure and supernatants were collected and analyzed using cytometric bead array. The concentration of inflammatory cytokines was measured using cytometric bead array (CBA; BD Biosciences, USA) as described previously [74]. This assay is multiplexed and measures the concentration of each cytokine simultaneously. Mean of fluorescence intensity were converted to cytokine concentration $(\mathrm{pg} / \mathrm{mL})$ using a standard curve for each cytokine measured. Graphs were plotted using GraphPad Prism.

\section{Diarrheogenic activity}

The diarrheogenic activity was measured by observing wet area distance of tail from mouse anus. Any area more than $2 \mathrm{~mm}$ indicated positive diarrhea cases. Each group consisted of 17 mice and the observation lasted $48 \mathrm{~h}$ in all experiments.

\section{Thermometry}

Temperatures were measured $1 \mathrm{~h}$ before and 1, 2, 4, 6, 8, 24 , and $48 \mathrm{~h}$ after LPS i.p. injection. Temperatures were 
measured using non-Contact Infrared Thermometer (EXtech Instruments, Model 42,505) as described [75, 76]. The mice were manually restrained, exposing the ventral aspect of the body. Body temperature was measured by aiming the thermometer at the animal's abdomen.

\section{Murine macrophage cell line RAW264.7 and J774A.1 and CEACAM1 siRNA}

Murine macrophage cell line RAW264.7 (ATCC RIB-7 $^{\mathrm{mm}}$ ) and 7774A.1 (ATCC ${ }^{\circ}$ TIB-67 ${ }^{\mathrm{mm}}$ ) were cultured for $24 \mathrm{~h}$ after seeding, then transfected with CEACAM1 small interfering RNA(siRNA) or scrambled control siRNA (Origene, Rockville, MD 20850, USA) according to manufacturer's protocol. After $24 \mathrm{~h}, 48 \mathrm{~h}$ and $72 \mathrm{~h}$ of transfection, cells were harvested and stained with mouse CEACAM1 APC-con jugated antibody (R\&D systems, Inc., Minneapolis, MN 55413, USA) to verify the silencing effect of CEACAM1. After silencing CEACAM1 for $48 \mathrm{~h}$, CEACAM1 could not be detected on RAW264.7 and J774A.1 cells. RAW264.7 and J774A.1 cells were treated with $500 \mathrm{ng} / \mathrm{mL}$ LPS over time shown in the figures or with BFA plus $500 \mathrm{ng} / \mathrm{mL}$ LPS for $5 \mathrm{~h}$, then cells were harvested and analyzed using qPCR or intracellular staining. For detection of IL-6 level in the supernatant, supernatant were harvested and analyzed using cytometric bead array.

\section{Immunoblot analysis and immunoprecipitation (IP)}

After $10 \mathrm{mg} / \mathrm{kg}$ i.p. injection of LPS for $2 \mathrm{~h}$, Liver, spleen and duodenum of both WT and Ceacam1 ${ }^{-/-}$mice were harvested separately, homogenized and lysed in 1\% NP-40 lysis buffer as previously described [64]. Total protein $(50 \mu \mathrm{g})$ was separated by SDS-gel polyacrylamide electrophoresis, transferred to nitrocellulose membranes and probed with either anti-mouse phospho-gp130 (Clone A-12, Santa Cruz Biotechnology), anti-mouse phosphoSTAT1, anti-mouse phospho-STAT3, anti-mouse SOCS3 or anti- $\beta$-actin antibody (Cell signaling technology, Danvers, MA 01923). Signals were detected on the Odyssey Infrared Imaging System (LI-COR Biosciences, Lincoln, NE, USA).

Bone marrow monocytes also were negatively isolated using EasySep ${ }^{\text {Tw }}$ Mouse Monocyte Enrichment Kit (StemCell Technologies Inc., Vancouver, Canada) according to manufacture protocol. Negatively isolated bone marrow monocytes with $1 \times 10^{6}$ concentration in RPMI 1640 medium supplement with 10\% FBS and antibiotics. After incubation in the presence or absence LPS for $15 \mathrm{~min}$, cells were harvested and lysed on ice for $30 \mathrm{~min}$, and protein concentration was determined using the Bio-Rad protein assay. Immunoprecipitation (IP) of RP105 or CEACAM1 was performed with anti-CEACAM1 (Clone MAb-CC1, Biolegend, San Diego, CA) or RP105 (Clone $\mathrm{RP} / 14$ ) using Pierce protein A/G plus agarose (Thermo Scientific, Rockford, IL) per the manufacturer's protocol, immunoblotted with appropriate primary antibodies (anti-MD1 pAb from Santa Cruz Biotechnology, Inc., Dallas, TX.; anti-RP105 pAb and anti-CD14 pAb from Abcam, Cambridge, MA; phospho-VAV1 Y160 pAb from Bioss Antibodies Inc., Woburn, MA; VAV1 pAb, SHP1 pAb, phospho-SHP-1 Y564 pAb, Src, and 4G10 pAb from Cell Signaling Technology, Inc., Danvers, MA; anti- $\beta$-actin $\mathrm{mAb}$ from GeneTex, Inc., Irvine, $\mathrm{CA}$ ) and infrared-labeled IRDye secondary antibodies. Detection was carried out using the Odyssey infrared imaging [77].

\section{Statistical analysis}

Assay results were expressed as means \pm SEM and paired or unpaired Student's t-tests were used for comparisons. All $p$-values are two-sided. Data were analyzed with GraphPad Prism software (version 5.0, GraphPad Software, San Diego, CA, USA).

\section{Additional file}

\begin{abstract}
Additional file 1: Figure S1. $I L-6$ mRNA expression in peritoneal cavity tissues after LPS challenge. Figure S2. Intracellular IL-6 and TNFa staining of hepatocytes and Kupffer cells in response to LPS in Ceacam1-/- mice. Figure S3. IL-6 and TNFa levels of liver cells after LPS treatment in vitro and IL-6 receptor downstream signaling activation after i.p. LPS in vivo. Figure S4. CEACAM1 expression on bone marrow CD115+ (M-CSF+) cells and CD115+ cell pattern change of bone marrow cells after treated with LPS + BFA. Figure S5. Macrophages are not involved in the early IL-6 response $(<2$ h) to LPS. Figure S6. RAW264.7 cells start to produce IL-6 after treatment with LPS + BFA for $11 \mathrm{~h}$, while silencing of CEACAM1 does not affect IL-6 production in murine macrophage RAW264.7 cells at the $2 \mathrm{~h}$ and $24 \mathrm{~h}$ time points. Figure S7. Murine macrophage cell line J774A.1 does not produce IL-6 within $5 \mathrm{~h}$ after LPS treatment, while silencing of CEACAM1 does not interfere with IL-6 production after LPS treatment at $2 \mathrm{~h}$ and $24 \mathrm{~h}$ points. Figure S8. PTP inhibitor III, a SHP1 inhibitor, increases levels of phospho-VAV1 in bone marrow monocytes of WT mice. Figure S9. CEACAM1, TLR4 and RP105 expression on human peripheral blood monocytes. (PDF $1828 \mathrm{~kb}$ )
\end{abstract}

\section{Abbreviations}

BCR: B-cell receptor; CEACAM1: Carcinoembryonic antigen 1 related antigen; EGFR: Epidermal growth factor receptor; G-CSFR: Granulocyte colony stimulating factor receptor 1; i.p: Intraperitoneal; IL-6: Interleukin 6; ITIM: Immunoreceptor tyrosine based inhibitory motif;

LPS: lipopolysaccharide; SHP-1: Src homology region containing phosphatase 1; SOSC3: Suppressor of cytokine signaling 3; STAT: Signal transducer and activator of transcription; TLR4: Toll like receptor 4; TNFa: Tumor necrosis factor alpha

\section{Acknowledgements}

The authors thank Dr. Angel Gu, Frances Chang, Courtni Salinas and Jennifer Chean in our laboratory and Dr. Walter Tsark in animal facility for technical support. The authors thank flow cytometry core for cell sorting and small animal imaging core for PET imaging.

\section{Author contributions}

Z.Z. and J.E.S. developed the concept and prepared the manuscript. Z.Z. designed experiments and carried out the experiments and the statistical analyses. D.L.P. performed animal experiment and qPCR. T.N. performed IP and immunoblot analysis. M.K. carried out FAM-LPS staining of tissues, interpretation of results, writing a section of the ms and proofing of the final ms. K.L. help design, carry out and proofing of the ms for all animal experiments. L.L. conjugated LPS with DOTA and FAM. All authos have read and approved the final version of this $\mathrm{ms}$. 


\section{Funding}

A portion of this study was supported by NIH grant CA84202. NIH had no role in the design of this study, the collection of data, analysis, and interpretation in the writing of this manuscript.

\section{Availability of data and materials}

All original data can be obtained by writing jshively@coh.org.

\section{Ethics approval and consent to participate}

The animal studies were carried out according to the Guide for the Care and Use of Laboratory Animals of National Institutes of Health. The protocol (number 08017) was approved by the Institutional Animal Care and Use Committee (IACUC) of the City of Hope, an AAALAC approved facility (assurance number A3001-01).

\section{Consent for publication}

Not applicable.

\section{Competing interests}

The authors declare no conflicts of interest.

\section{Publisher's Note}

Springer Nature remains neutral with regard to jurisdictional claims in published maps and institutional affiliations.

\section{Received: 26 September 2018 Accepted: 11 January 2019} Published online: 23 January 2019

\section{References}

1. Calabrese LH, Rose-John S. IL-6 biology: implications for clinical targeting in rheumatic disease. Nat Rev Rheumatol. 2014;10(12):720-7.

2. Harden LM, du Plessis I, Poole S, Laburn HP. Interleukin (IL)-6 and IL-1 beta act synergistically within the brain to induce sickness behavior and fever in rats. Brain Behav Immun. 2008;22(6):838-49.

3. Kimura A, Kishimoto T. IL-6: regulator of Treg/Th17 balance. Eur J Immunol. 2010:40(7):1830-5.

4. Maggio M, Guralnik JM, Longo DL, Ferrucci L. Interleukin-6 in aging and chronic disease: a magnificent pathway. J Gerontol A Biol Sci Med Sci. 2006; 61(6):575-84.

5. Grossman RM, Krueger J, Yourish D, Granelli-Piperno A, Murphy DP, May LT, Kupper TS, Sehgal PB, Gottlieb AB. Interleukin 6 is expressed in high levels in psoriatic skin and stimulates proliferation of cultured human keratinocytes. Proc Natl Acad Sci U S A. 1989:86(16):6367-71.

6. Rincon M. Interleukin-6: from an inflammatory marker to a target for inflammatory diseases. Trends Immunol. 2012:33(11):571-7.

7. Nilsberth C, Elander L, Hamzic N, Norell M, Lonn J, Engstrom L, Blomqvist A. The role of interleukin- 6 in lipopolysaccharide-induced fever by mechanisms independent of prostaglandin E2. Endocrinology. 2009;150(4):1850-60.

8. Chai Z, Gatti S, Toniatti C, Poli V, Bartfai T. Interleukin (IL)-6 gene expression in the central nervous system is necessary for fever response to lipopolysaccharide or IL-1 beta: a study on IL-6-deficient mice. J Exp Med. 1996:183(1):311-6.

9. Nakajima A, lijima H, Neurath MF, Nagaishi T, Nieuwenhuis EE, Raychowdhury R, Glickman J, Blau DM, Russell S, Holmes KV, et al. Activation-induced expression of carcinoembryonic antigen-cell adhesion molecule 1 regulates mouse T lymphocyte function. J Immunol. 2002;168(3):1028-35.

10. Dankner M, Gray-Owen SD, Huang YH, Blumberg RS, Beauchemin N CEACAM1 as a multi-purpose target for cancer immunotherapy. Oncoimmunology. 2017;6(7):e1328336

11. Dery KJ, Kujawski M, Grunert D, Wu X, Ngyuen T, Cheung C, Yim JH, Shively JE. IRF-1 regulates alternative mRNA splicing of carcinoembryonic antigenrelated cell adhesion molecule 1 (CEACAM1) in breast epithelial cells generating an immunoreceptor tyrosine-based inhibition motif (ITIM) containing isoform. Mol Cancer. 2014;13:64.

12. Pan H, Shively JE. Carcinoembryonic antigen-related cell adhesion molecule1 regulates granulopoiesis by inhibition of granulocyte colony-stimulating factor receptor. Immunity. 2010:33(4):620-31.

13. Lu R, Pan H, Shively JE. CEACAM1 negatively regulates IL-1 beta production in LPS activated neutrophils by recruiting SHP-1 to a SYK-TLR4-CEACAM1 complex. PLoS Pathog. 2012;8(4):e1002597.
14. Poy MN, Yang Y, Rezaei K, Fernstrom MA, Lee AD, Kido Y, Erickson SK, Najjar SM. CEACAM1 regulates insulin clearance in liver. Nat Genet. 2002;30(3):270-6

15. Abou-Rjaily GA, Lee SJ, May D, Al-Share QY, Deangelis AM, Ruch RJ, Neumaier M, Kalthoff H, Lin SH, Najjar SM. CEACAM1 modulates epidermal growth factor receptor--mediated cell proliferation. J Clin Invest. 2004;114(7):944-52.

16. Lobo EO, Zhang Z, Shively JE. Pivotal advance: CEACAM1 is a negative coreceptor for the $\mathrm{B}$ cell receptor and promotes CD19-mediated adhesion of B cells in a PI3K-dependent manner. J Leukoc Biol. 2009:86(2):205-18.

17. Chen Z, Chen L, Baker K, Olszak T, Zeissig S, Huang YH, Kuo TT, Mandelboim $\mathrm{O}$, Beauchemin $\mathrm{N}$, Lanier $\mathrm{LL}$, et al. CEACAM1 dampens antitumor immunity by down-regulating NKG2D ligand expression on tumor cells. J Exp Med. 2011:208(13):2633-40.

18. Fiori $V$, Magnani M, Cianfriglia M. The expression and modulation of CEACAM1 and tumor cell transformation. Ann Ist Super Sanita. 2012;48(2):161-71.

19. Gray-Owen SD, Blumberg RS. CEACAM1: contact-dependent control of immunity. Nat Rev Immunol. 2006;6(6):433-46.

20. Shively JE. CEACAM1 and hyperplastic polyps: new links in the chain of events leading to colon cancer. Oncogene. 2004:23(58):9303-5.

21. Werner MF, Fraga D, Melo MC, Souza GE, Zampronio AR. Importance of the vagus nerve for fever and neutrophil migration induced by intraperitoneal LPS injection. Inflamm Res. 2003;52(7):291-6.

22. Poltorak A, He X, Smirnova I, Liu MY, Van Huffel C, Du X, Birdwell D, Alejos E, Silva M, Galanos C, et al. Defective LPS signaling in C3H/HeJ and C57BL/ 10ScCr mice: mutations in Tlr4 gene. Science. 1998;282(5396):2085-8.

23. Hoshino K, Takeuchi O, Kawai T, Sanjo H, Ogawa T, Takeda Y, Takeda K, Akira S. Cutting edge: toll-like receptor 4 (TLR4)-deficient mice are hyporesponsive to lipopolysaccharide: evidence for TLR4 as the Lps gene product. J Immunol. 1999;162(7):3749-52.

24. Akashi S, Shimazu R, Ogata H, Nagai Y, Takeda K, Kimoto M, Miyake K. Cutting edge: cell surface expression and lipopolysaccharide signaling via the toll-like receptor 4-MD-2 complex on mouse peritoneal macrophages. J Immunol. 2000;164(7):3471-5.

25. Zhang FX, Kirschning CJ, Mancinelli R, Xu XP, Jin Y, Faure E, Mantovani A, Rothe M, Muzio M, Arditi M. Bacterial lipopolysaccharide activates nuclear factor-kappaB through interleukin-1 signaling mediators in cultured human dermal endothelial cells and mononuclear phagocytes. J Biol Chem. 1999; 274(12):7611-4.

26. Muzio M, Bosisio D, Polentarutti N, D'Amico G, Stoppacciaro A, Mancinelli R, van't Veer C, Penton-Rol G, Ruco LP, Allavena P, et al. Differential expression and regulation of toll-like receptors (TLR) in human leukocytes: selective expression of TLR3 in dendritic cells. J Immunol. 2000;164(11):5998-6004.

27. Cartmell T, Poole S, Turnbull AV, Rothwell NJ, Luheshi GN. Circulating interleukin-6 mediates the febrile response to localised inflammation in rats. J Physiol. 2000:526(Pt 3):653-61.

28. Kozak W, Kluger MJ, Soszynski D, Conn CA, Rudolph K, Leon LR, Zheng H. IL-6 and IL-1 beta in fever. Studies using cytokine-deficient (knockout) mice. Ann N Y Acad Sci. 1998;856:33-47.

29. Bauer J, Ganter U, Geiger T, Jacobshagen U, Hirano T, Matsuda T, Kishimoto T, Andus T, Acs G, Gerok W, et al. Regulation of interleukin- 6 expression in cultured human blood monocytes and monocyte-derived macrophages. Blood. 1988;72(4):1134-40

30. Callery MP, Kamei T, Flye MW. Endotoxin stimulates interleukin-6 production by human Kupffer cells. Circ Shock. 1992;37(3):185-8.

31. Helfgott DC, May LT, Sthoeger Z, Tamm I, Sehgal PB. Bacterial lipopolysaccharide (endotoxin) enhances expression and secretion of beta 2 interferon by human fibroblasts. J Exp Med. 1987;166(5):1300-9.

32. Reyes TM, Fabry Z, Coe CL. Brain endothelial cell production of a neuroprotective cytokine, interleukin-6, in response to noxious stimuli. Brain Res. 1999:851(1-2):215-20.

33. Verma S, Nakaoke R, Dohgu S, Banks WA. Release of cytokines by brain endothelial cells: a polarized response to lipopolysaccharide. Brain Behav Immun. 2006;20(5):449-55.

34. Andreasen AS, Kelly M, Berg RM, Moller K, Pedersen BK. Type 2 diabetes is associated with altered NF-kappaB DNA binding activity, JNK phosphorylation, and AMPK phosphorylation in skeletal muscle after LPS. PLoS One. 2011;6(9):e23999.

35. Panesar N, Tolman K, Mazuski JE. Endotoxin stimulates hepatocyte interleukin-6 production. J Surg Res. 1999;85(2):251-8.

36. Saad B, Frei K, Scholl FA, Fontana A, Maier P. Hepatocyte-derived interleukin-6 and tumor-necrosis factor alpha mediate the 
lipopolysaccharide-induced acute-phase response and nitric oxide release by cultured rat hepatocytes. Eur J Biochem. 1995;229(2):349-55.

37. Flower L, Gray R, Pinkney J, Mohamed-Ali V. Stimulation of interleukin-6 release by interleukin-1 beta from isolated human adipocytes. Cytokine. 2003;21(1):32-7.

38. Ringheim GE, Burgher KL, Heroux JA. Interleukin-6 mRNA expression by cortical neurons in culture: evidence for neuronal sources of interleukin-6 production in the brain. J Neuroimmunol. 1995;63(2):113-23.

39. Vallieres $L$, Rivest $S$. Regulation of the genes encoding interleukin-6, its receptor, and gp130 in the rat brain in response to the immune activator lipopolysaccharide and the proinflammatory cytokine interleukin-1beta. J Neurochem. 1997;69(4):1668-83.

40. Woodroofe MN, Sarna GS, Wadhwa M, Hayes GM, Loughlin AJ, Tinker A, Cuzner ML. Detection of interleukin-1 and interleukin-6 in adult rat brain, following mechanical injury, by in vivo microdialysis: evidence of a role for microglia in cytokine production. J Neuroimmunol. 1991;33(3):227-36.

41. Sawada M, Suzumura A, Marunouchi T. TNF alpha induces IL-6 production by astrocytes but not by microglia. Brain Res. 1992;583(1-2):296-9.

42. Benveniste EN, Sparacio SM, Norris JG, Grenett HE, Fuller GM. Induction and regulation of interleukin- 6 gene expression in rat astrocytes. J Neuroimmunol. 1990:30(2-3):201-12.

43. Beurel E, Jope RS. Lipopolysaccharide-induced interleukin-6 production is controlled by glycogen synthase kinase- 3 and STAT3 in the brain. J Neuroinflammation. 2009;6:9.

44. Hamzic N, Tang Y, Eskilsson A, Kugelberg U, Ruud J, Jonsson Jl, Blomqvist A, Nilsberth C. Interleukin-6 primarily produced by non-hematopoietic cells mediates the lipopolysaccharide-induced febrile response. Brain Behav Immun. 2013;33:123-30.

45. Hettinger J, Richards DM, Hansson J, Barra MM, Joschko AC, Krijgsveld J, Feuerer M. Origin of monocytes and macrophages in a committed progenitor. Nat Immunol. 2013;14(8):821-30.

46. Seshadri S, Duncan MD, Hart JM, Gavrilin MA, Wewers MD. Pyrin levels in human monocytes and monocyte-derived macrophages regulate IL-1beta processing and release. J Immunol. 2007;179(2):1274-81.

47. Netea MG, Nold-Petry CA, Nold MF, Joosten LA, Opitz B, van der Meer JH, van de Veerdonk FL, Ferwerda G, Heinhuis B, Devesa I, et al. Differential requirement for the activation of the inflammasome for processing and release of IL-1beta in monocytes and macrophages. Blood. 2009;113(10): 2324-35.

48. Yona S, Kim KW, Wolf Y, Mildner A, Varol D, Breker M, Strauss-Ayali D, Viukov $S$, Guilliams M, Misharin A, et al. Fate mapping reveals origins and dynamics of monocytes and tissue macrophages under homeostasis. Immunity. 2013; 38(1):79-91.

49. Greenhill CJ, Rose-John S, Lissilaa R, Ferlin W, Ernst M, Hertzog PJ, Mansell A, Jenkins BJ. IL-6 trans-signaling modulates TLR4-dependent inflammatory responses via STAT3. J Immunol. 2011;186(2):1199-208.

50. Chang Q, Daly L, Bromberg J. The IL-6 feed-forward loop: a driver of tumorigenesis. Semin Immunol. 2014;26(1):48-53.

51. Hacker $\mathrm{H}$, Tseng PH, Karin M. Expanding TRAF function: TRAF3 as a tri-faced immune regulator. Nat Rev Immunol. 2011;11(7):457-68.

52. Kawai T, Akira S. The role of pattern-recognition receptors in innate immunity: update on toll-like receptors. Nat Immunol. 2010;11(5):373-84.

53. Fidler JM. The induction of hapten-specific immunological tolerance and immunity in B lymphocytes. VI. Differential tolerance susceptibility in adult spleen as a function of B-cell maturation level. J Exp Med. 1979;150(3):491-506.

54. Yazawa N, Fujimoto M, Sato S, Miyake K, Asano N, Nagai Y, Takeuchi O, Takeda K, Okochi H, Akira S, et al. CD19 regulates innate immunity by the toll-like receptor RP105 signaling in B lymphocytes. Blood. 2003;102(4):1374-80.

55. Hebeis B, Vigorito E, Kovesdi D, Turner M. Vav proteins are required for Blymphocyte responses to LPS. Blood. 2005;106(2):635-40.

56. DeFranco AL. Vav and the B cell signalosome. Nat Immunol. 2001;2(6):482-4.

57. Miyake K, Yamashita Y, Hitoshi Y, Takatsu K, Kimoto M. Murine B cell proliferation and protection from apoptosis with an antibody against a 105kD molecule: unresponsiveness of X-linked immunodeficient B cells. J Exp Med. 1994;180(4):1217-24.

58. Hunter CA, Jones SA. IL-6 as a keystone cytokine in health and disease. Nat Immunol. 2015;16(5):448-57.

59. Shi C, Jia T, Mendez-Ferrer S, Hohl TM, Serbina NV, Lipuma L, Leiner I, Li MO, Frenette PS, Pamer EG. Bone marrow mesenchymal stem and progenitor cells induce monocyte emigration in response to circulating toll-like receptor ligands. Immunity. 2011;34(4):590-601.
60. Palsson-McDermott EM, O'Neill LA. Signal transduction by the lipopolysaccharide receptor, toll-like receptor-4. Immunology. 2004;113(2):153-62.

61. Fitzgerald KA, Rowe DC, Barnes BJ, Caffrey DR, Visintin A, Latz E, Monks B, Pitha PM, Golenbock DT. LPS-TLR4 signaling to IRF-3/7 and NF-kappaB involves the toll adapters TRAM and TRIF. J Exp Med. 2003;198(7):1043-55.

62. Vaure C, Liu Y. A comparative review of toll-like receptor 4 expression and functionality in different animal species. Front Immunol. 2014;5:316.

63. Ketloy C, Engering A, Srichairatanakul U, Limsalakpetch A, Yongvanitchit $K_{\text {, }}$ Pichyangkul S, Ruxrungtham K. Expression and function of toll-like receptors on dendritic cells and other antigen presenting cells from non-human primates. Vet Immunol Immunopathol. 2008;125(1-2):18-30.

64. Gu A, Zhang Z, Zhang N, Tsark W, Shively JE. Generation of human CEACAM1 transgenic mice and binding of Neisseria Opa protein to their neutrophils. PLoS One. 2010;5(4):e10067.

65. Miyake K, Yamashita Y, Ogata M, Sudo T, Kimoto M. RP105, a novel B cell surface molecule implicated in B cell activation, is a member of the leucinerich repeat protein family. J Immunol. 1995;154(7):3333-40.

66. Yamashita Y, Miyake K, Miura Y, Kaneko Y, Yagita H, Suda T, Nagata S, Nomura J, Sakaguchi N, Kimoto M. Activation mediated by RP105 but not CD40 makes normal B cells susceptible to anti-lgM-induced apoptosis: a role for fc receptor coligation. J Exp Med. 1996;184(1):113-20.

67. Nagai Y, Watanabe Y, Takatsu K. The TLR family protein RP105/MD-1 complex: a new player in obesity and adipose tissue inflammation. Adipocyte. 2013;2(2):61-6.

68. Nagai Y, Kobayashi T, Motoi Y, Ishiguro K, Akashi S, Saitoh S, Kusumoto Y, Kaisho T, Akira S, Matsumoto M, et al. The radioprotective 105/MD-1 complex links TLR2 and TLR4/MD-2 in antibody response to microbial membranes. J Immunol. 2005;174(11):7043-9.

69. Lu R, Niesen MJ, Hu W, Vaidehi N, Shively JE. Interaction of actin with carcinoembryonic antigen-related cell adhesion molecule 1 (CEACAM1) receptor in liposomes is Ca2+- and phospholipid-dependent. J Biol Chem. 2011;286(31):27528-36.

70. Divanovic S, Trompette A, Atabani SF, Madan R, Golenbock DT, Visintin A, Finberg RW, Tarakhovsky A, Vogel SN, Belkaid Y, et al. Negative regulation of toll-like receptor 4 signaling by the toll-like receptor homolog RP105. Nat Immunol. 2005;6(6):571-8.

71. Ungefroren $\mathrm{H}$, Hyder $\mathrm{A}$, Schulze M, Fawzy El-Sayed KM, Grage-Griebenow $\mathrm{E}$, Nussler AK, Fandrich F. Peripheral blood monocytes as adult stem cells: molecular characterization and improvements in culture conditions to enhance stem cell features and proliferative potential. Stem Cells Int. 2016; 2016:7132751.

72. Zhang C, Xin H, Zhang W, Yazaki PJ, Zhang Z, Le K, Li W, Lee H, Kwak L, Forman $S$, et al. CD5 binds to Interleukin-6 and induces a feed-forward loop with the transcription factor STAT3 in B cells to promote Cancer. Immunity. 2016:44(4):913-23.

73. Triantafilou K, Triantafilou M, Fernandez N. Lipopolysaccharide (LPS) labeled with Alexa 488 hydrazide as a novel probe for LPS binding studies. Cytometry. 2000:41(4):316-20.

74. Samineni S, Zhang Z, Shively JE. Carcinoembryonic antigen-related cell adhesion molecule 1 negatively regulates granulocyte colony-stimulating factor production by breast tumor-associated macrophages that mediate tumor angiogenesis. Int J Cancer. 2013;133(2):394-407.

75. Adamson TW, Diaz-Arevalo D, Gonzalez TM, Liu X, Kalkum M. Hypothermic endpoint for an intranasal invasive pulmonary aspergillosis mouse model. Comp Med. 2013;63(6):477-81.

76. Bast DJ, Yue M, Chen X, Bell D, Dresser L, Saskin R, Mandell LA, Low DE, de Azavedo JC. Novel murine model of pneumococcal pneumonia: use of temperature as a measure of disease severity to compare the efficacies of moxifloxacin and levofloxacin. Antimicrob Agents Chemother. 2004;48(9):3343-8.

77. Nguyen T, Chen CJ, Shively JE. Phosphorylation of CEACAM1 molecule by calmodulin kinase IID in a three-dimensional model of mammary gland lumen formation. J Biol Chem. 2014;289(5):2934-45. 